\title{
A low-temperature co-fired ceramic micro-reactor system for high-efficiency on-site hydrogen production
}

\author{
Bo Jiang a, b, Thomas Maeder ${ }^{b}$, Alejandro J. Santis-Alvarez ${ }^{c}$, Dimos Poulikakos ${ }^{\text {, }}$, \\ Paul Muralt ${ }^{\mathrm{a}, *}$ \\ ${ }^{a}$ Ceramics Laboratory, EPFL, Lausanne, Switzerland \\ ${ }^{\mathrm{b}}$ Laboratory of Micro-engineering for Manufacturing, EPFL, Lausanne, Switzerland \\ ${ }^{c}$ Laboratory of Thermodynamics in Emerging Technologies, ETH Zurich, Zurich, Switzerland
}

\section{H I G H L I G H T S}

- Novel high-temperature micro reaction system based on the LTCC technology.

- Demonstrated on-site, self sustained syngas production for micro SOFC applications.

- Built-in heater for ramping up temperature.

- Excellent thermal insulation, low power dissipation of integrated system.

-Well distributed flow inside micro reactor for high reforming efficiency.

\section{A R T I C L E I N F O}

\section{Article history:}

Received 28 April 2014

Received in revised form

2 September 2014

Accepted 11 September 2014

Available online 19 September 2014

\section{Keywords:}

LTCC

Micro-reactor

Hydrogen production

Solid oxide fuel cells

\begin{abstract}
A B S T R A C T
A ceramic-based, meso-scale fuel processor for on-board production of syngas fuel was demonstrated for applications in micro-scale solid-oxide fuel cells ( $\mu$-SOFCs). The processor had a total dimension of $12 \mathrm{~mm} \times 40 \mathrm{~mm} \times 2 \mathrm{~mm}$, the gas reforming micro reactor occupying the hot end of a cantilever had outer dimensions of $12 \times 18 \mathrm{~mm}$. The device was fabricated through a novel progressive lamination process in low-temperature co-fired ceramic (LTCC) technology. Both, heating function and desired fluidic structures were integrated monolithically into the processor. Using catalytic partial oxidation of a hydrocarbon fuel (propane) as a reaction model, a thermally self-sustaining hydrogen production was achieved. The output flow is sufficiently high to drive an optimized single membrane $\mu$ SOFC cell of about the same footprint as the micro reactor. Microsystem design, fabrication, catalyst integration as well as the chemical characterization are discussed in detail.
\end{abstract}

\section{Introduction}

Electrical power supplies for portable electronic devices are subject to important challenges, as current battery technologies cannot raise energy density at the pace of increased power consumption in portable applications. As a consequence, the autonomy of devices such as smart phones, digital cameras, etc. is rather limited. An alternative technology is to store energy in chemical form as a fuel, and then to convert fuel into electrical energy by means of fuel cells. Even if considering an overall fuel cell system efficiency of $15 \%$ only, the achievable output energy densities (e.g. $\sim 7.4 \mathrm{MJ} \mathrm{kg}^{-1}$ for propane, $\sim 3.0 \mathrm{MJ} \mathrm{kg}^{-1}$ for methanol) are greatly larger than the ones of Li-ion batteries $\left(\sim 0.9 \mathrm{MJ} \mathrm{kg}^{-1}\right)[1,2]$.

\footnotetext{
* Corresponding author. Tel.: +4121 6934957; fax: +41216935810

E-mail address: paul.muralt@epfl.ch (P. Muralt).
}

Therefore, mesa or micro fuel cells are currently studied and developed intensively as a replacement of batteries. Micro-scale solid-oxide fuel cells ( $\mu$-SOFCs) appear to be very promising, because they exhibit higher efficiencies and a better compatibility with chemical fuels (no CO poisoning issue) as compared to protonexchange membrane fuel cells. The $\mu$-SOFCs require, however, much higher operating temperatures of over $400{ }^{\circ} \mathrm{C}$ to achieve meaningful power densities. To avoid carbon coking at electrode materials, it is preferred to reform the hydrocarbon fuels (e.g. propane) into syngas $\left(\mathrm{H}_{2}+\mathrm{CO}\right)$ with an on-site fuel processor. Current reforming technologies for on-site syngas production include steam reforming (SR), catalytic partial oxidation (CPOX) and auto-thermal/oxidative steam reforming (ATR/OSR) $[3,4]$.

In $\mu$-SOFCs, such an on-site reforming process cannot be carried out in a large conventional reactor because of the following 
requirements: (i) compact and miniaturized integration into $\mu$ SOFCs, (ii) accurate control of reforming reactions, and (iii) short start-up time and rapid transition to off-state mode. The microreactor technology is widely considered as a robust solution for on-site hydrogen production from hydrocarbon fuels $[2,4]$. The dramatic reduction of characteristic lengths within micro-reactors greatly enhances mass and heat transport, minimizes catalyst materials, improves process stability against thermal runaway, and thus facilitates process control. Last but not least, micro reactors can be realized with dimensions in the millimetre range, which is the right size for integration in $\mu$-SOFCs devices.

To date, various micro-reactors for on-site syngas production have been developed [5-11]. Microchannel and packed-bed types of micro-reactors fabricated from stainless steels have been used for the SR of methanol operated in a temperature range of $250^{\circ} \mathrm{C}-450^{\circ} \mathrm{C}[6]$. Despite their advantages, such as easy machining and high mechanical strength, the metal-based micro-reactors are limited in downscaling by their high thermal conductivity, and lower power-to-mass ratio because of their high density. Alternatively, silicon-based microfabricated micro-reactors were studied for fuel reforming processes, for instance, for high-temperature $\left(>400{ }^{\circ} \mathrm{C}\right) \mathrm{CPOX}$ processes of methane [5]. High-resolution micro fabrication enables fine structures that improve heat transfer, for instance by using a suspended-tube configuration [12], while simultaneously providing fluidic functional structures, such as stoppers for easy catalyst installation [13]. Moreover, heating elements and temperature sensors can be integrated via thin-film technology for monitoring and control of the chemical process. However, major difficulties are encountered with silicon based microreaction systems. Firstly, silicon is thermo-mechanically incompatible with most materials that are used in micro solid oxide fuel cells: the coefficient of thermal expansion (CTE) in silicon and common $\mu$-SOFC building materials are $3 \times 10^{-6} \mathrm{~K}^{-1}$ and $10 \times 10^{-6} \mathrm{~K}^{-1}$ respectively [1], and thus differ considerably. Silicon is a good heat conductor, and thus cannot serve to bridge the device to a (cold) housing. In addition, silicon technology is rather expensive.

For these reasons, we recently proposed ceramic- and glassbased micro-reactors for high-temperature reforming reactions [9,14-16]. Hotz et al. [9] developed a disk-shaped micro-reactor made of quartz glass and achieved high selectivity of $\mathrm{H}_{2}$ (92\%) and $\mathrm{CO}(82 \%)$ species via CPOX of butane at $550{ }^{\circ} \mathrm{C}$. In a previous work $[14,17]$, we developed an aluminoborosilicate glass-based micro hot plate on which a micro reformer for syngas production was integrated by glass sealing. Its efficient thermal decoupling allowed a thermally self-sustaining CPOX syngas production above $500{ }^{\circ} \mathrm{C}$, and served to demonstrate an integrated $\mu$-SOFC unit for producing a power density of $50 \mathrm{~mW} \mathrm{~cm}{ }^{-2}$ at $\sim 550{ }^{\circ} \mathrm{C}$. However, the utilized glass materials system (especially the sealing glass) was found to be somewhat fragile to thermal shock under operation cycles, which we ascribed to high thermal gradients and resulting mechanical stresses arising from the low thermal conductivity of glass. In addition, glass seals for joining fluidic components (e.g. the microreactor chamber) are problematic, and silicate glasses are not easy to machine. We thus focused on ceramic-based micro-reactors. These are intrinsically more suited for on-site syngas production because ceramics exhibit (i) an excellent chemical resistance; (ii) a higher mechanical strength than the used glass material; and (iii) a thermal conductivity that can mitigate hot-spot formation. Both (ii) and (iii) allow in turn selection of materials with higher CTE that is matched with $\mu$-SOFC materials.

Among ceramic technologies, low-temperature co-fired ceramic technology (LTCC) enables production of micro-reactors in a fast prototyping approach and at low cost $[7,8,18]$. A typical LTCC fabrication process involves mechanical structuration of LTCC green tapes (unfired state) and integration of thick-film functional materials via screen printing technologies. Afterwards, all tapes are stacked and laminated together under a hot pressing process $\left(\sim 70{ }^{\circ} \mathrm{C}\right)$. This laminate is sintered in a one-step process at temperatures of $850^{\circ} \mathrm{C}-900^{\circ} \mathrm{C}$ to form a monolithic and rigid ceramic module. In our case, such a module aims at having integrated functional materials and embedded 3-dimensional fluidic structures with optimized heat transfer properties and miniaturization. The LTCC technology is considered as a very attractive solution for functional packaging in $\mu$ SOFC applications because of its easy and low-cost fluidic structuration processes, its high material stability, and good compatibility with thick-film technology. The CTE of LTCC material is generally higher than that of silicon, in fact close to materials of an oxide fuel cell membrane, but with a CTE mismatch issue when the latter are inside a silicon frame. However, this problem can be overcome by a metallic hermetic bonding that joins silicon and ceramic materials, as explored in Refs. [19,20]. Park et al. [8] has demonstrated a fully integrated fuel processor for the hydrogen production via the SR of methanol. This system included several fluidic components such as a vaporizer, a SR reactor, a heat exchanger and a preferential CO oxidation (PrOX) reactor, producing about $0.26 \mathrm{~W}$ in terms of hydrogen chemical energy (at $300^{\circ} \mathrm{C}$ ) for the fuel cells. Furthermore, Belavič et al. [18] reported a multifunctional LTCC-based fuel processor that combined both fluidic components such as an evaporator, steam reformer, a combustor and additional heating/sensing functions i.e. thick-film heating element and pressure gauges.

Previous work clearly showed the promising potential of microreactors for on-site hydrogen (or syngas) production. However, published literature on integrated micro reactor systems able to deliver thermally self-sustaining syngas production in a plug-andplay manner is still scant. Therefore, we present here a meso-scale LTCC-based micro-reforming system for on-site syngas production. The CPOX of propane (Reaction (1)) was chosen for this study due to the abovementioned BOP advantages over SR/OSR that no complex water management was required and it easily achieved a thermally self-sustaining reforming process) [21]. The used catalyst in this study, composed of rhodium $(\mathrm{Rh})$ and $(\mathrm{Ce}, \mathrm{Zr}) \mathrm{O}_{2}$ nanoparticles, has demonstrated a high syngas yield as well as a high resistance to coke formation in the temperature range of $400-700{ }^{\circ} \mathrm{C}$ [22]. The advantage of LTCC technology lies in its flexibility to realize microfluidic structures such as channels, its integration of temperature sensors as well as heating elements. Besides, LTCC remains an economic fabrication technology. The main highlights of this work are:

- Demonstration of a millimetre-scale LTCC micro-reactor $\left(40 \times 12 \times 1.8 \mathrm{~mm}^{3}\right)$ for the on-site syngas production via the CPOX of propane at above $500{ }^{\circ} \mathrm{C}$ in a thermally self-sustaining manner; a process that is advantageous from a balance-of-plant (BOP) perspective for small devices, as it obviates the need of both an auxiliary heat source and a water management accessory.

- The new lamination process for integrating fine fluidic structures within the micro-reactor;

- The effect of a thick-film metallic thermal spreader for improving thermal uniformity and syngas production performance of the LTCC reactor;

- A novel symmetric cross-flow design for improved syngas yields within the LTCC micro-reactor.

\section{System design}

\subsection{Thermal management}

The thermal management plays a critical role to the efficiency of high-temperature micro-reactor systems. Downscaling is 
associated with several advantages, such as low startup energy and good internal thermal coupling, allowing e.g. heat from exothermic reactions to be utilized to drive endothermic ones in order to maintain overall system temperature. However, the risk of too large heat losses increases dramatically due to an increasing surface to volume ratio. Moreover, as the reactor temperature increases to $400{ }^{\circ} \mathrm{C}-700{ }^{\circ} \mathrm{C}$, common fluidic/electrical interfaces become unreliable, requiring more cumbersome and costly bonding and interconnection techniques. In conventional reactors, these issues can be solved by adding large-scale thermal insulation and extended tubing for thermal decoupling. This approach is obviously not practical to a micro-reactor system, as it would greatly reduce the volumetric efficiency and increase the dead volume of the system to non-acceptable extent. Therefore, an efficient concept must be developed for separating the micro-reactor into two thermally decoupled zones: a high-temperature region (hot-zone) for the syngas production, which would also host $\mu$-SOFCs and post-combustor, and a low temperature area (cold-zone) for convenient fluidic and electrical interconnections.

Another important consideration in the micro-reactor design concerns thermal uniformity of the CPOX reaction region. Studies [23-25] suggested that there are two main zones in the CPOX reactor that are associated with different reaction paths inside the packed-bed reactor: (a) In the entrance region, all oxygen is consumed by fast exothermic combustion of a large portion of the hydrocarbon fuel (30\% of propane) with a risk of hot spot formation (see Reaction (2) with using propane as an example); (b) In the outlet region, the remaining fuel is converted to syngas through reactions with the water and carbon dioxide produced in the entrance region (see Reaction (3) and (4)). The involved reduction reactions are slow and endothermic, and are going on over a larger zone in the downstream path. Several experimental studies evidenced hot spot formation near the reactor entrance, followed by a "cold" downstream area [25,26].

$\mathrm{C}_{3} \mathrm{H}_{8}+1.5 \mathrm{O}_{2} \stackrel{\text { catalyst }}{\longrightarrow} 3 \mathrm{CO}+4 \mathrm{H}_{2}, \Delta H_{298}^{0}=-227 \mathrm{~kJ} \mathrm{~mol}^{-1}$

(Reaction 1)

$\mathrm{C}_{3} \mathrm{H}_{8}+5 \mathrm{O}_{2} \stackrel{\text { catalyst }}{\longrightarrow} 3 \mathrm{CO}_{2}+4 \mathrm{H}_{2} \mathrm{O}, \Delta \mathrm{H}<0$

(Reaction 2)

$\mathrm{C}_{3} \mathrm{H}_{8}+3 \mathrm{H}_{2} \mathrm{O} \stackrel{\text { catalyst }}{\longrightarrow} 3 \mathrm{CO}+7 \mathrm{H}_{2}, \Delta H>0$

(Reaction 3)

$\mathrm{C}_{3} \mathrm{H}_{8}+3 \mathrm{CO}_{2} \stackrel{\text { catalyst }}{\longrightarrow} 6 \mathrm{CO}+4 \mathrm{H}_{2}, \Delta H>0$

(Reaction 4)
Thermal imbalance between the hot combustion region and cold reforming region leads to an inefficient syngas production, i.e. to an incomplete reformation of the fuel due to missing heat near the outlet. Therefore the reactor design must provide means to reduce thermal imbalance through enhanced heat transfer from the hot to the "cold" zone. One idea would be the use of highly thermal conductive materials for constructing reactor walls. For avoiding increased thermal losses to the ambient, this heat transfer enhancement must be done locally in the reaction zone only.

\subsection{Reactor design}

Based on those considerations, we propose a LTCC micro-reactor design as shown in Fig. 1, which shows a superposition of functional components within a monolithic device together with material information. The reactor was designed as a cantilever beam with two working zones: a hot-zone for the syngas production process at one end, and a cold-zone for fluidic/electrical interconnections. A slender structure with air gaps links both working zones and provides thermal decoupling. The bridge structure consisted of three LTCC beams, two narrow ones at the sides (1.0 mm wide) and a main one in the centre ( $2.4 \mathrm{~mm}$ wide). This approach enabled effective thermal decoupling with only $7 \mathrm{~mm}$ long bridges: the hot zone temperature reached above $600{ }^{\circ} \mathrm{C}$, while the cold zone temperature remained below $100{ }^{\circ} \mathrm{C}$ [27]. A similar design can be found in silicon-based micro-reactors [12,28], with the difference that the high thermal conductivity of silicon materials requires a more sophisticated thermal decoupling structure. A "larger" glassbased micro-reactor with a similar cantilever shape for thermal decoupling was reported in our previous and forthcoming work $[15,29]$. This system achieved a good thermal decoupling by using a combination of low thermal conductivity of glass $\left(1.16 \mathrm{~W} \mathrm{~m}{ }^{-1} \mathrm{~K}^{-1}\right.$ at $25^{\circ} \mathrm{C}$ [30]) and a long cantilever geometric design, since structuring glass in a bridge configuration was relatively impractical. The LTCC approach presented in this study takes half the volume as compared above glass version, and it thus more favourable for miniaturization. In addition, the LTCC technology is much more amenable for integrating complex fluidic devices.

In the hot-zone of our LTCC micro-reactors, a thick-film Pt heater was embedded between the reactor chamber on the top and the fluidic exit chamber beneath, providing a heater function to the device (see Fig. 1). Thin-film platinum heaters are widely used in silicon-based micro-reactors, providing fast and efficient heating at a small scale $\left(<1 \mathrm{~mm}^{2}\right)$. However, thin-film Pt tends to degrade at temperature over $600{ }^{\circ} \mathrm{C}$ by the island formation, altering its electrical conductivity [31]. Besides, it is very difficult to grow

Functional components

Materials

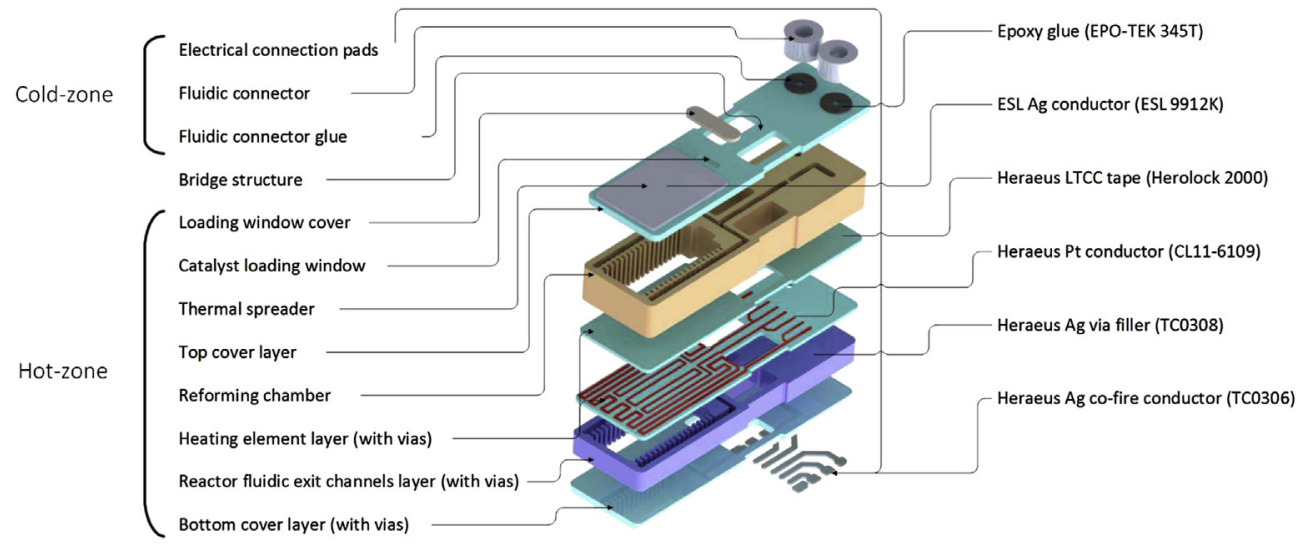

Fig. 1. A schematic view of the LTCC micro-reactor design. 
dense thin films on the surface of fired LTCC. In contrast, thick-film platinum heating elements are easily integrated and operated due to their good compatibility with LTCC technology, and robustness at high temperature $\left(>500{ }^{\circ} \mathrm{C}\right)[27,32]$.

In the hot zone of the LTCC micro-reactor, the chamber above the heater layer serves for the CPOX process in this work. A micro packed-bed type of reactor ( $\mu$-PBR) was chosen here instead of a microchannel design. A main advantage of using $\mu$-PBR is its flexible catalyst placement: the reactor not only avoids any specific catalyst incorporation development, but also widens the catalyst inventory in comparison to other types of micro-reactors. Additionally, the uniform flow distribution over porous beds can be more readily achieved than with other types [22]. The pressure drop along the packed bed can be engineered by optimizing dimensions and porosity of the packed-bed [9].

The fluidic inlet channels were placed at both lateral sides in order to increase the contact area in the entry region of the packedbed, and to improve the thermal uniformity. A micro flow distributing structure was designed, containing a series of parallel short, 0.6-0.35 mm wide microchannels for improving the flow dispersion of reactants within the packed-bed. Four lets in the middle heater layer form the exit to the fluidic chamber beneath the heaters. The top cover of the packed-bed chamber contains a small opening $\left(3.3 \times 0.9 \mathrm{~mm}^{2}\right)$ for loading the catalyst. Above this cover, a thick-film silver metallization layer was added as a thermal spreader for enhancing the thermal conductivity of the upper reactor walls. In the low-temperature zone, the fluidic interconnections were installed on the top side to connect in and outlets. Thick-film solder pads for the electrical interconnection of heaters were fabricated at the backside of the reactor.

\subsection{The flow distributing design}

In order to examine the effectiveness of the gas-distributing structure, a two-dimensional computational fluid dynamics (CFD) model was developed to evaluate a velocity distribution of the gas fluid within a simplified symmetric reactor structure (Fig. 2a). In this model, a gas was considered to flow into the fluidic inlet channel ( $0.8 \mathrm{~mm}$ wide), through the distributor, and into a porous media that was considered as the packed-bed. Four exits at the
Table 1

Parameters for the CFD simulation.

\begin{tabular}{lll}
\hline Properties & Value & Unit \\
\hline Fluid density $-\rho$ & 1.185 & $\mathrm{~kg} \mathrm{~m}^{-3}$ \\
Fluid viscosity $-\mu$ & $1.98 \times 10^{-5}$ & $\mathrm{~Pa} \mathrm{~s}$ \\
Packed-bed porosity $-\varepsilon$ & 0.38 & - \\
Packed-bed permeability $-k$ & $1.05 \times 10^{-11}$ & $\mathrm{~m}^{2}$ \\
Temperature $-T$ & 298 & $\mathrm{~K}$ \\
\hline
\end{tabular}

other side of the packed-bed play the role of these four fluidic lets through the heater layer for connecting the packed bed to the fluidic exit chamber. The flow was modelled as an incompressible $(\mathrm{Ma} \leq 1)$ and laminar flow in the main and the distributor fluidic channels. Parameters regarding to flow conditions and packed-bed properties are given in Table 1 . The velocity distribution results have shown in Fig. 2 for two different flows. The simulated distribution structure contained 17 microchannels with a length of $1 \mathrm{~mm}$ and varied widths from $0.35 \mathrm{~mm}$ to $0.7 \mathrm{~mm}$. A flow velocity of $0.6 \mathrm{~m} \mathrm{~s}^{-1}$ at entrance of the main channel decreased to below $0.1 \mathrm{~m} \mathrm{~s}^{-1}$ at the exits. The microchannels showed a decrease of flow velocity from 0.3 to about $0.02 \mathrm{~m} \mathrm{~s}^{-1}$ with increasing distance away from the entry. This drop was partially compensated by the increasing diameters of the distributor channels. As a result, about $70 \%$ of the packed-bed area exhibited a relatively homogenous velocity distribution. The relative velocity distribution improved at higher flow rate $\left(2.3 \mathrm{~m} \mathrm{~s}^{-1}\right.$ at the entry, see Fig. $\left.2 \mathrm{c}\right)$, resulting in an increased homogeneous area $(\sim 85 \%)$ inside the micro reactor. The numerical model demonstrated that the inlet flow could be distributed more evenly in a certain (higher) flow range by using a number of parallel microchannels, whose widths was optimized to balance the flow from the main channel. The dimensions of the small, short distributing channels were much smaller than the main inlet channel, so that the pressure drop (assumed as laminar flow with the Hagen-Poiseuille relationship) in the distributing channels was much higher than that in the main inlet channel. In addition, the higher flow resistance of the outlet holes, as compared to the one of the micro-reactor, leads to a pressure drop concentration at the outlet holes, and assures that the pressure drop inside the micro reactor is limited and thus assuring a more homogeneous flow.

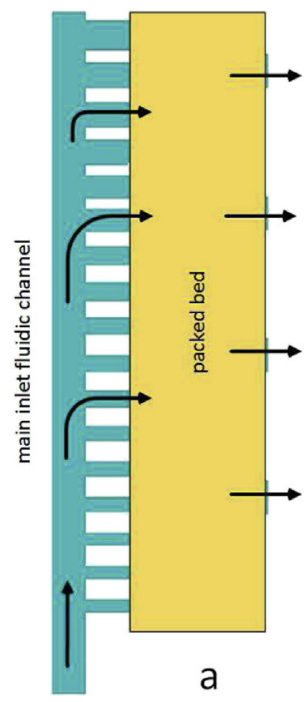

A symmetric flow distributor model

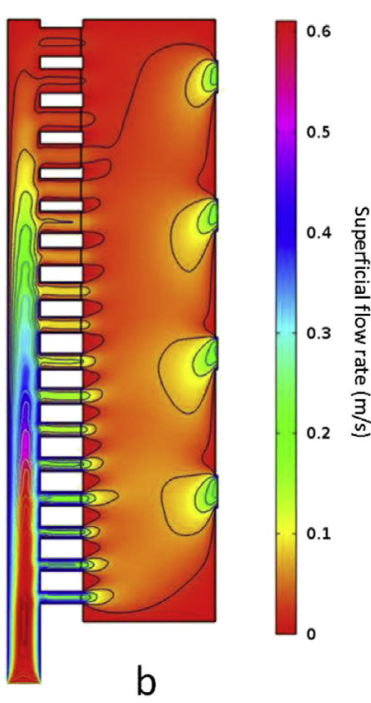

Flow rate: $30 \mathrm{ml} / \mathrm{min}$

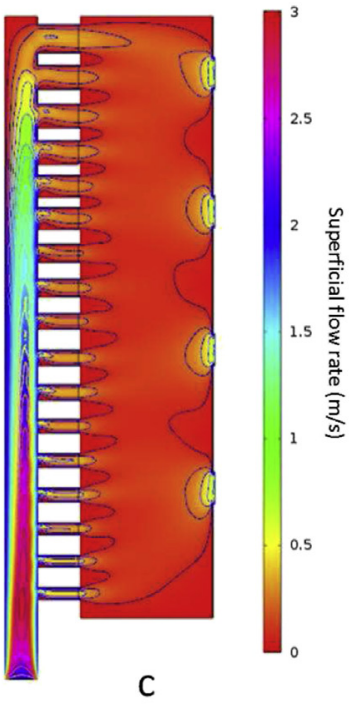

Flow rate: $100 \mathrm{ml} / \mathrm{min}$

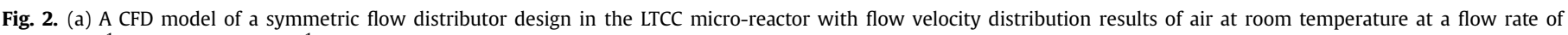

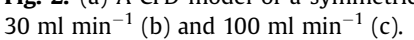


Top view

island fluidic structure
Cross-section view

fluidic channel
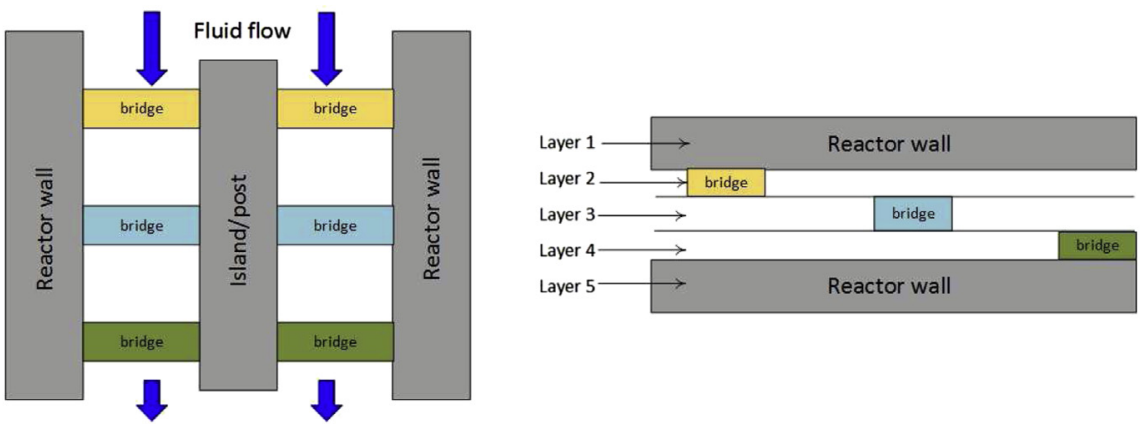

Fig. 3. A schematic view of the fluidic channels in the island structure of the LTCC micro-reactor

\section{Experimentals}

\subsection{Fabrication of the LTCC micro-reactor}

A CAD program (Hyde) was used to design fluidic and electrical heater (via and connection pads) layouts for the LTCC microreactors. The designed fluidic structure was then transferred and patterned at each LTCC tape (Heraeus Heralock ${ }^{\circledR} 2000,133 \mu \mathrm{m}$ thickness) by a laser cutting process (Nd-YAG laser, wavelength $1064 \mathrm{~nm}, 3 \mathrm{~W}$ output, $50 \mu \mathrm{m}$ spot size; LS 9000, Laser Systems, Germany). The main fluidic channels along the lateral sides of the packed-bed were $0.8 \mathrm{~mm}$ wide. In order to maintain continuity and avoid separation of the LTCC material between the flow distribution channels, a bridge cutting method was applied (see Fig. 3). Details of this LTCC fine fluidic structure fabrication process can be found in the available literature [33].

Due to limited resolution of the used laser cutting process, a minimal distance of $0.3 \mathrm{~mm}$ had to be respected between neighbouring microchannels in the flow distributor, which constrained the maximum microchannel width to $0.55 \mathrm{~mm}$, i.e. narrower than the simulated geometry with the widest channel of $0.7 \mathrm{~mm}$. The packed-bed chamber had an area of $14.8 \times 6.6 \mathrm{~mm}^{2}$. Four fluidic slots $\left(0.5 \times 0.8 \mathrm{~mm}^{2}\right)$ for connecting the packed-bed chamber to the exit fluidic channels were placed at centre of the heater layer, having a distance of $2.6 \mathrm{~mm}$ between each other.

Next, thick-film platinum heaters (CL11-6109, Heraeus, Germany), electrical solder pads (TC0306, Heraeus, Germany) and electrical vias (TC0308, Heraeus, Germany) were screen-printed (Aurel C900, Italy) onto the designated LTCC tapes, each of which followed by a drying process at $80^{\circ} \mathrm{C}$ for $10 \mathrm{~min}$. The printed thickfilm Pt heater comprised two individual heating elements, inner and outer, for a better control of the heating uniformity [27].

Hot uniaxial pressing was carried out for the LTCC lamination process. Those LTCC tapes with the same fluidic layout were first stacked and laminated as functional layers to build up the designed height of fluidic channels and cavities (see Fig. 3) with a lamination pressure of $\sim 20 \mathrm{MPa}$ for $10 \mathrm{~min}$ at room temperature. Secondly, these laminated "functional layers" were stacked and laminated at
$70{ }^{\circ} \mathrm{C}$ with a lamination pressure of $\sim 4 \mathrm{MPa}$ for $15 \mathrm{~min}$. The integrated laminate was finally fired at a peak temperature of $850^{\circ} \mathrm{C}$ for 30 min with a ramp rate of $2{ }^{\circ} \mathrm{C} \mathrm{min}^{-1}$ in air (ATV PEO-601 lamp furnace, ATV Technologie GmbH, Germany) to become a monolithic piece. Details of this lamination and firing process are summarized in Table 2.

To integrate the thermal spreader, a thick-film silver ink (ESL 9912K, ESL ElectroScience, USA) was screen-printed onto top side of the fired LTCC micro-reactor, followed by a drying process at $120^{\circ} \mathrm{C}$ for $10 \mathrm{~min}$, and a firing process at a peak temperature of $850^{\circ} \mathrm{C}$ for $10 \mathrm{~min}$. To connect fluidic pipes (Fig. 4), two stainless steel screw fluidic connectors (CN-M3-PK-3, FESTO, Switzerland) were attached at the in/outlets of the LTCC micro-reactor by an epoxy glue (EPO-TEK 345T), which was cured at $100{ }^{\circ} \mathrm{C}$ for $2 \mathrm{~h}$.

\subsection{Catalyst loading}

For incorporating the catalyst nanoparticles into out LTCC micro-reactor, a kind of inert catalyst support was required as a carrier for forming the packed bed. Several embedding processes have been studied to allow convenient filling of catalyst nanoparticles into meso-scale packed-bed reactors [29,34]. However, cracks or large voids were easily formed during the filling and following thermal treatments. The most optimized simple filling process was finally realized with catalyst pellets containing yttrium-stabilized zirconia spheres $(\sim 0.15 \mathrm{~mm}$ in diameter) as supports onto which the catalyst nanoparticles $(\sim 6.6 \mathrm{~nm}$ in diameter) were attached via a dry milling process. Due to their large surface energy, these catalyst nanoparticles attached easily on the surface of the YSZ spheres by Van der Waals forces. Advantages of these YSZ spheres were their narrow particle size distribution, good fluidity, and mechanical/chemical inertness, which allowed for a randomly packed catalytic bed inside the LTCC micro-reactor with minor risks for cracking or large void formation. Their low heat conductivity $\left(\sim 2 \mathrm{~W} \mathrm{~m}^{-1} \mathrm{~K}^{-1}\right.$ at $\left.500{ }^{\circ} \mathrm{C}[35]\right)$ may be a disadvantage to the packed-bed from a heat transfer point of view, though. The catalyst pellets were prepared as follows in weight: $15 \%$ of catalyst nanoparticles and $85 \%$ of calcined, washed and

Table 2

Lamination and firing processes for the LTCC micro-reactor fabrication.

\begin{tabular}{|c|c|c|c|c|c|}
\hline Functional layer & \# Tapes & $\begin{array}{l}\text { Estimated fired } \\
\text { thickness (mm) }\end{array}$ & Pre-lamination & Lamination & Firing \\
\hline Cover & $\times 2$ & 0.15 & $100 \mathrm{KN}, 25^{\circ} \mathrm{C}, 10 \mathrm{~min}$ & \multirow[t]{5}{*}{$25 \mathrm{KN}, 70^{\circ} \mathrm{C}, 15 \mathrm{~min}$} & $25^{\circ} \mathrm{C}-450{ }^{\circ} \mathrm{C}$ by $2{ }^{\circ} \mathrm{C} \mathrm{min}^{-1}$ \\
\hline Reforming chamber & $\times 12$ & 0.92 & $100 \mathrm{KN}, 25^{\circ} \mathrm{C}, 10 \mathrm{~min}$ & & $450{ }^{\circ} \mathrm{C}-850{ }^{\circ} \mathrm{C}$ by $10^{\circ} \mathrm{C} \mathrm{min}^{-1}$ \\
\hline Heater & $\times 3$ & 0.23 & $100 \mathrm{KN}, 25^{\circ} \mathrm{C}, 10 \mathrm{~min}$ & & $850{ }^{\circ} \mathrm{C}$ for $20 \mathrm{~min}$ \\
\hline Flow exit channels & $\times 4$ & 0.30 & $100 \mathrm{KN}, 25^{\circ} \mathrm{C}, 10 \mathrm{~min}$ & & $850^{\circ} \mathrm{C}-25^{\circ} \mathrm{C}$ by $20^{\circ} \mathrm{C} \mathrm{min}^{-1}$ \\
\hline Bottom cover & $\times 2$ & 0.15 & $100 \mathrm{KN}, 25^{\circ} \mathrm{C}, 10 \mathrm{~min}$ & & \\
\hline
\end{tabular}




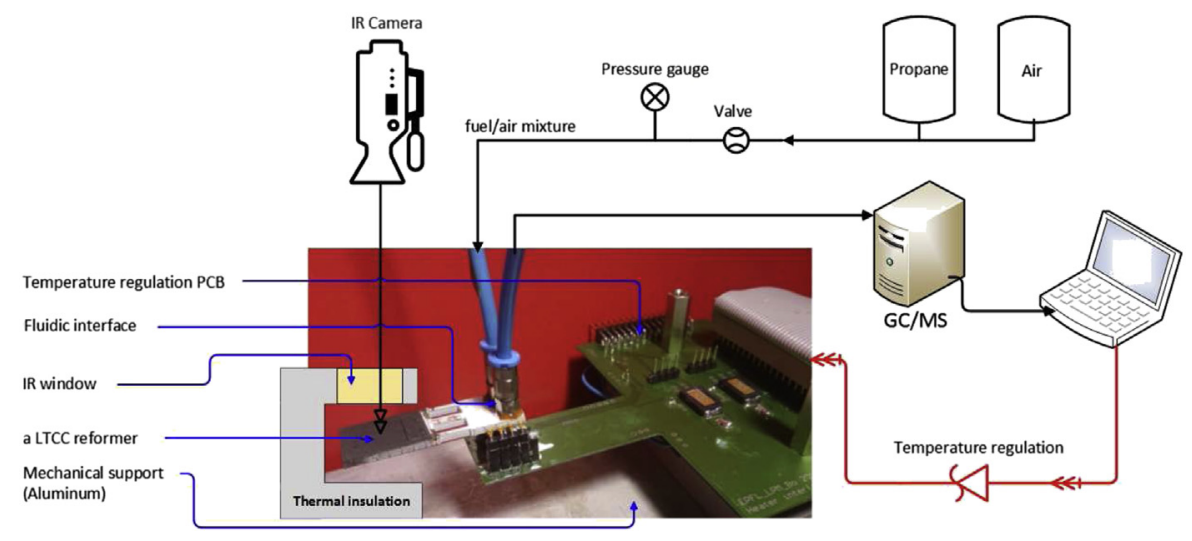

Fig. 4. A schematic view of the LTCC micro-reactor measurement setup.

dried YSZ spheres were mixed via a dry milling process without additional milling media for $4 \mathrm{~h}$. The surface area of as-prepared catalyst pellets were evaluated by Brunauer-Emmett-Teller (BET) measurements (AutoChem II 2920, Micromeritics Instrument Corp., USA). They were then filled into as-fabricated LTCC microreactors through the loading window (indicated in Fig. 1). Afterwards, the loading window was sealed with a LTCC cap by a thickfilm sealing glass (ESL 4026-A, ESL ElectroScience, USA) at $700{ }^{\circ} \mathrm{C}$ for $20 \mathrm{~min}$.

\subsection{Measurement setup}

The LTCC micro-reactor was mounted onto a testing platform for functional characterization (see Fig. 4). In this platform, a printed circuit board (PCB) was developed for regulating applied electrical power, measuring resistance of thick-film Pt heaters for the temperature sensing, and housing the LTCC micro-reactor. Two thermal insulation blocks (WDS ${ }^{\circledR}$ Ultra, Porextherm Dämmstoffe $\mathrm{GmbH}$ Germany) covered the hot-zone of the LTCC micro-reactor for better insulation. Each block measured $50 \times 70 \times 25 \mathrm{~mm}^{3}$ and exhibited a thermal conductivity from 0.018 to $0.031 \mathrm{~W} \mathrm{~m}^{-1} \mathrm{~K}^{-1}$ in the temperature range of $50-600{ }^{\circ} \mathrm{C}$. An opening of $25 \times 14 \mathrm{~mm}^{2}$ was created at the top thermal insulation cover, where a piece of zinc selenide crystal was inserted as an infrared window for the thermographic characterization. A heat sink (ICK SMD F21-SA, Fischer Elektronik GmbH, Germany; not shown) with a nominal thermal resistance of $33{ }^{\circ} \mathrm{C} \mathrm{W}^{-1}$ was attached at the cold zone of the LTCC micro-reactor for improving its heat dissipation to the ambient environment. An aluminium plate offered an overall mechanical support. The regulation of the applied electrical power to the thick-film heaters as well as the temperature sensing were achieved by an in-house LabView program. More details can be found in a forthcoming article [29]. Such a portable micro-reactor system can be directly connected to a feedstock supply for performing high temperature chemical reactions and laboratory instruments for a chemical analysis. Additionally, characterization tools such as pressure gauges or thermographic instruments can easily be added to this system.

\subsection{Characterization}

The optical inspection of the fabricated structures was carried out with a Leica M165C microscope (Leica Microsystem Germany). The resistance of both thick-film heaters was measured via a fourwire method, eliminating contact resistance and improving the measurement accuracy. The temperature dependence of resistance (TCR) was experimentally determined for the thick-film heaters to serve later for the temperature sensing. Details of this TCR calibration procedure can be found in the Ref. [27]. In such a way, the supplied electrical power, in another words the thermal power supplied electrically, and an operating temperature $\left(T_{\mathrm{op}}\right)$ at the reactor hot-zone were obtained. Thermometric observations were accomplished by an infrared camera (FLIR SC655, spectral range 7.5-13 $\mu \mathrm{m}$, FLIR Inc. USA). The pressure drop through the LTCC micro-reactor was measured by a pressure gauge (Honeywell 26PC, Honeywell International, Inc. USA) that was installed next to the inlet of the reactor, while the outlet was at ambient atmosphere. Air was used as the carrier fluid for the pressure drop measurement at room temperature. The flow was regulated by a mass flow controller (Smart HSC, Vögtlin Instrument AG, Switzerland).

The fuel gas consisted of LPG propane (purity: 99.95\%, PanGas, Switzerland) that was diluted with synthetic air (80 vol.\% $\mathrm{N}_{2}$, 20 vol.\% $\mathrm{O}_{2}$, Purity $99.9996 \%$, PanGas, Switzerland) at $\sim 20{ }^{\circ} \mathrm{C}$. The dilution ratio between propane and air, or the so-called fuel to oxygen C/O mole ratio was set as 0.8 (see Equation (1)). This ratio was shown to be optimal for the CPOX of propane with the used catalyst [16].

$$
\begin{aligned}
& \phi=2 \frac{\dot{n}_{\mathrm{C}_{3} \mathrm{H}_{8}, \text { in }}}{\dot{n}_{\mathrm{O}_{2}, \text { in }}} \\
& \eta_{\text {propane }}=\frac{\dot{n}_{\mathrm{C}_{3} \mathrm{H}_{8}, \text { in }}-\dot{n}_{\mathrm{C}_{3} \mathrm{H}_{8}, \text { out }}}{\dot{n}_{\mathrm{C}_{3} \mathrm{H}_{8}, \text { in }}} \\
& \psi_{\mathrm{H}_{2}}=\frac{\dot{n}_{\mathrm{H}_{2}, \text { out }}}{5 \dot{n}_{\mathrm{C}_{3} \mathrm{H}_{8}, \mathrm{in}}} \\
& \psi_{\text {syngas }}=\frac{\dot{n}_{\mathrm{H}_{2}}+\dot{n}_{\mathrm{CO}}}{7 \cdot \dot{n}_{\mathrm{C}_{3} \mathrm{H}_{8}, \text { in }}} \\
& \operatorname{Re}=Q \cdot \frac{D_{\mathrm{H}} \cdot \rho_{\mathrm{f}}}{A \cdot \mu_{\mathrm{f}}} \\
& R_{\mathrm{t}}=R_{\mathrm{ref}} \cdot\left[1+a \cdot \Delta T+b \cdot \Delta T^{2}\right], \text { where } \Delta T=T_{\mathrm{t}}-T_{\mathrm{ref}} \\
& \text { Ca }=\frac{r_{\mathrm{obs}}}{k_{\mathrm{g}} \cdot a^{\prime} \cdot C_{\mathrm{b}}} \\
& k_{\mathrm{g}}=\frac{\mathrm{Sh} \cdot D_{\mathrm{m}}}{L^{\prime}}
\end{aligned}
$$

$\mathrm{Sh}=2.0+1.8 \cdot \operatorname{Re}^{1 / 2} \cdot \mathrm{Sc}^{1 / 3}$ 
$\frac{D_{\mathrm{m}, T_{1}}}{D_{\mathrm{m}, T_{2}}}=\frac{T_{1}}{T_{2}} \cdot \frac{\mu_{T_{2}}}{\mu_{T_{1}}}$

$L^{\prime}=\frac{d_{\text {particle }}}{6}$

Two process methods were applied for evaluating the CPOX performance in the LTCC micro-reactor: (1) the constanttemperature mode and (2) the self-sustained mode. In the constant-temperature mode, a nominal operation temperature $\left(T_{\mathrm{op}}\right)$ of the thick-film heaters was set throughout the CPOX reaction. A 30 standard cubic centimetre per minute $(\mathrm{sccm})$ flow rate of propane/air mixture was introduced to the LTCC micro-reactor. For keeping the $T_{\mathrm{op}}$ constant, the electrical power applied to the thickfilm Pt heaters was adapted to the evolving heat of the exothermic $\mathrm{CPOX}$ reaction. In this way, reaction temperatures were controlled to the precision of the actual temperature uniformity in the micro reactor. In addition, we could experimentally simulate external heat sources such as a post-combustor of a $\mu$-SOFC, which could be used to supply heat for ramping up of the micro-reactor. It is also a good way to study the impact of heat transfer inside the LTCC micro-reactor during the self-sustaining mode by comparing the reactor efficiency with and without temperature stabilization and equilibration by the heaters.

The exhaust gas composition was analysed in an online automated gas chromatograph (6890 GC, with a HP-PlotQ column, Agilent Technologies USA). The propane conversion rate $(\eta)$ and the yields $(\psi)$ of $\mathrm{H}_{2}$ and syngas, were quantified by results of the gas analysis according to Equations (2)-(4).

\section{Results and discussion}

\subsection{The realized structure of the LTCC micro-reactor}

Fig. 5a shows an assembled LTCC micro-reactor with sealed catalyst load window, fluidic and electrical connectors. The overall dimension of the device was $40 \times 12 \times 2 \mathrm{~mm}^{3}$, containing a hot zone $\left(19.7 \times 12 \times 2 \mathrm{~mm}^{3}\right)$, a bridge structure $\left(7.3 \times 12 \times 2 \mathrm{~mm}^{3}\right)$ and a cold zone $\left(13 \times 12 \times 2 \mathrm{~mm}^{3}\right)$. The thermal spreader is seen from the top surface of the reactor in the hot zone, mainly covering the packed-bed area. The loading window was next to the packedbed region and capped by a glass-sealed LTCC piece. The sealing layer was off the bed position, minimizing the thermal impact from the packed-bed where hot spots may be formed by the CPOX process. The sealing glass had a high melting temperature $\left(>700{ }^{\circ} \mathrm{C}\right)$, which assured good thermal stability during high temperature operation $\left(<600{ }^{\circ} \mathrm{C}\right)$. The slender bridges structure separated the hot and cold zones. In the cold zone, the screw type fluidic interface enabled various standard fluidic connectors to be directly mounted. The epoxy sealing glue used here allowed for a continuous working temperature of $250^{\circ} \mathrm{C}$, largely above the maximally observed temperature of the cold zone $\left(<100{ }^{\circ} \mathrm{C}\right)$.

The thickness of the embedded thick-film Pt heaters was measured from optical cross-section images of the LTCC microreactor (Fig. 5b). The heater cross section was somewhat elliptic, with a larger thickness at the centre $(0.024 \mathrm{~mm})$ than at the edge $(0.015 \mathrm{~mm})$. A visual top view of the assembled LTCC micro-reactor is shown in Fig. 5a. Cross sections of this device were prepared for the visual inspection and the evaluation of fluidic structure and thick-film heaters (Fig. 5b). The catalyst pellets, containing Rh/ $(\mathrm{Ce}, \mathrm{Zr}) \mathrm{O}_{2}$ and $\mathrm{YSZ}$, were examined under an optical microscopy (Fig. 5c) (Leica M165C, Leica Microsystem Germany). The white YSZ spheres became dark because of the attached catalyst nanoparticles. It turned out that all elements were correctly fabricated, including also the main fluidic channels, the gas distributor channels, the packed-bed chamber, the exit flow channels, and the fluidic lets in the LTCC heaters layer (Fig. 5).

Fig. 5c shows the catalyst nanoparticles attached onto YSZ spheres. Evidently, the catalyst nanoparticles were well-attached to the YSZ surface and are partially agglomerated. The specific surface area of such catalyst-YSZ pellets was about $4.9 \mathrm{~m}^{2} \mathrm{~g}^{-1}$. This value was several times smaller than when using a quartz sand support $[29,34]$. The thermal conductivity of YSZ materials was about $3 \mathrm{~W} \mathrm{~m}^{-1} \mathrm{~K}^{-1}$ at $25{ }^{\circ} \mathrm{C}$ [35], smaller than that of silica quartz $\left(\sim 7 \mathrm{~W} \mathrm{~m}^{-1} \mathrm{~K}^{-1}\right.$ at $\left.27^{\circ} \mathrm{C}\right)$ [36]. However, the great fluidity and narrow particle size distribution of YSZ spheres resulted in a close packing of the catalytic bed, without cracks that were usually seen in packed beds made with impregnated materials [34,37]. In addition, such an easy attachment process for nanoparticle catalysts is beneficial to the catalyst screening and the micro-reactor prototyping, and thus significantly avoids the time-consuming development of a catalyst incorporation procedure.

The quality of the fluidic structure in the LTCC micro-reactor was evaluated in Fig. 6. When using the standard lamination processes, the thermo-compression can easily destroy the embedded fluidic structures. The use of sacrificial material methods, in which the fluidic structure is filled by sacrificial materials such as graphite

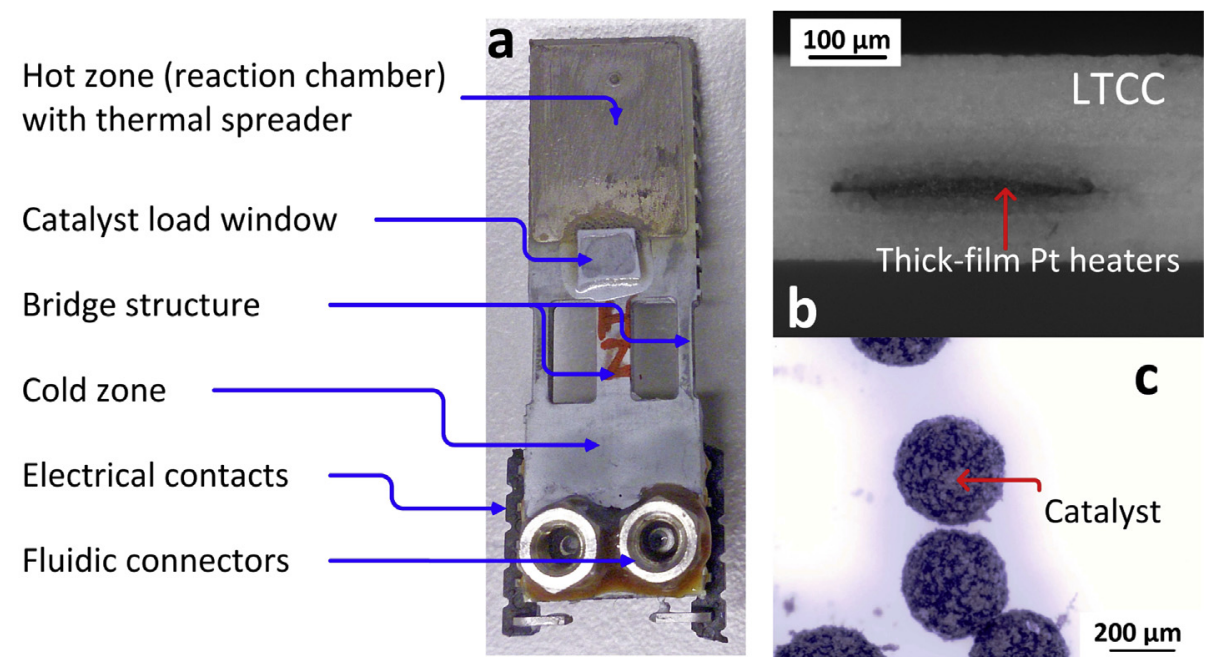

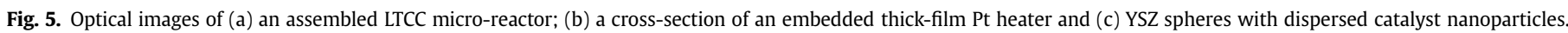



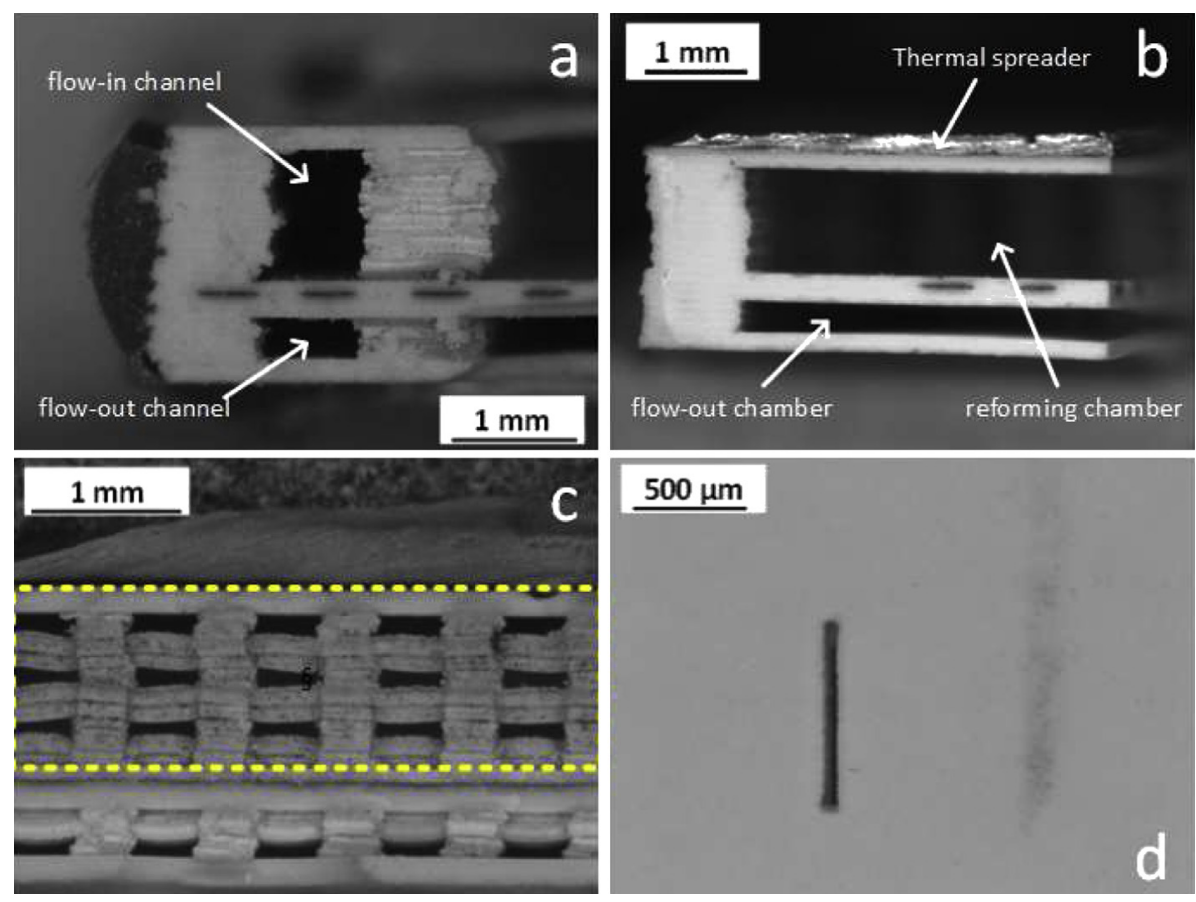

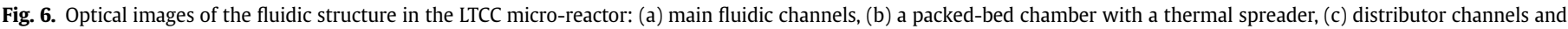
(d) fluidic vias in the heater layer.

[38], is able to provide a temporary physical support during LTCC lamination and firing processes. However, the height of fluidic structures is then limited by the thickness of screen printed sacrificial materials, i.e. about $100 \mu \mathrm{m}$, which is insufficient to create $\mathrm{mm}$ or sub-mm scale fluidic structures such as the packed-bed chamber of our application. Alternatively, the lamination process can be attained at room temperature by using additional adhesive materials [39]. However, for our application, more than 10 layers of LTCC tapes were usually involved. The content of additional organic adhesive materials would be excessive, considerably increasing the burnout time required to avoid delamination between LTCC tapes during firing. In contrast, the progressive lamination approach pursued in this work provided an optimal solution for creating $\mathrm{mm}$ or sub-mm scale fluidic structures. As seen from images of the LTCC micro-reactors, fluidic channels in sub-mm scale have been fabricated without observable deformations of the channel walls (Fig. 6a). The cross-section area of both flow-in and flow-out channels in the LTCC micro-reactor are about $1.05 \times 0.8 \mathrm{~mm}^{2}$ and $0.32 \times 0.8 \mathrm{~mm}^{2}$. Such sizes yielded a Reynolds number $(\mathrm{Re})$ value less than 150 for a $100 \mathrm{sccm}$ of air at even $500{ }^{\circ} \mathrm{C}$, indicating a laminar flow in the fluidic channels. The value of Re was estimated by Equation (5), where $Q$ was volumetric flow rate of the fluid, $D_{H}$ was hydraulic diameter of the fluidic channels in the LTCC microreactor, $\rho_{\mathrm{f}}$ was density of the fluid, $A$ was cross-section area, and $\mu_{\mathrm{f}}$ was dynamic viscosity of the fluid.

The cross-sectional image of the packed-bed chamber (Fig. 6b) showed that the heater layer was well sandwiched between the packed-bed chamber and the exit chamber. Accordingly a large area of suspending structure $\left(6.6 \times 14 \mathrm{~mm}^{2}\right)$ was produced with minimal deformation via our progressive lamination approach. Furthermore, the thick-film thermal spreader was well adhered on the top side wall of the packed-bed chamber with a thickness of $\sim 0.18 \mathrm{~mm}$.

Although the laser structuration in LTCC tapes usually can fabricate fine features $(50-100 \mu \mathrm{m})$ and cavities, it was usually limited for creating island or post array structures. These were usually cut off from main body of the tape. In order to fabricate multiple parallel microchannels in the gas distributor, we created a micro-bridging approach to link separated channel walls without the cutting off. As shown in Fig. 3, the position of bridges linking the reactor wall with the islands were different from layer to layer. In such a way, these bridges did not block the channels after being stacked together in 3-dimensions, while the island or post structure remained. With the bridge method, three openings were formed from each individual microchannel of the gas distributor (in yellow (in the web version)). As confirmed by the previous simulation studies, the placement of the gas distributor with multiple fluidic microchannels in parallel was able to distribute inlet flow to the packed-bed more evenly. A number of openings from the gas distributor instead of one for each microchannel can further improve the dispersion of this inlet flow into the packed-bed chamber. Fig. 6 shows one of the four exhaust slots $\left(0.05 \times 0.80 \mathrm{~mm}^{2}\right.$ per each $)$ of the symmetrical-flow reforming chamber. They were created in the centre of the thick-film heater layer.

\subsection{Fluidic characterization}

Fig. 7 shows the pressure drop from inlet to exit channels of the LTCC micro-reactor. The exit channels were at atmospheric pressure. The pressure was measured as difference to the ambient atmosphere between the flow control unit and the gas inlet. In absence of packed-bed catalyst packing, the pressure raised nearly linearly as the flow rate increased, due to a quite constant flow resistance of the fluidic channels. By design, the highest resistance was built at the lets in the thick-film heater layer. The use of small fluidic slots aimed at increasing the pressure drop at the exit of the reforming chamber and holding up the gas flow, which is known to improve the flow dispersion of reactants in the packed-bed chamber [40]. The pressure drop across the packed bed was obtained by subtracting the pressure drop observed with an empty catalyst chamber from the pressure drop observed at the device 


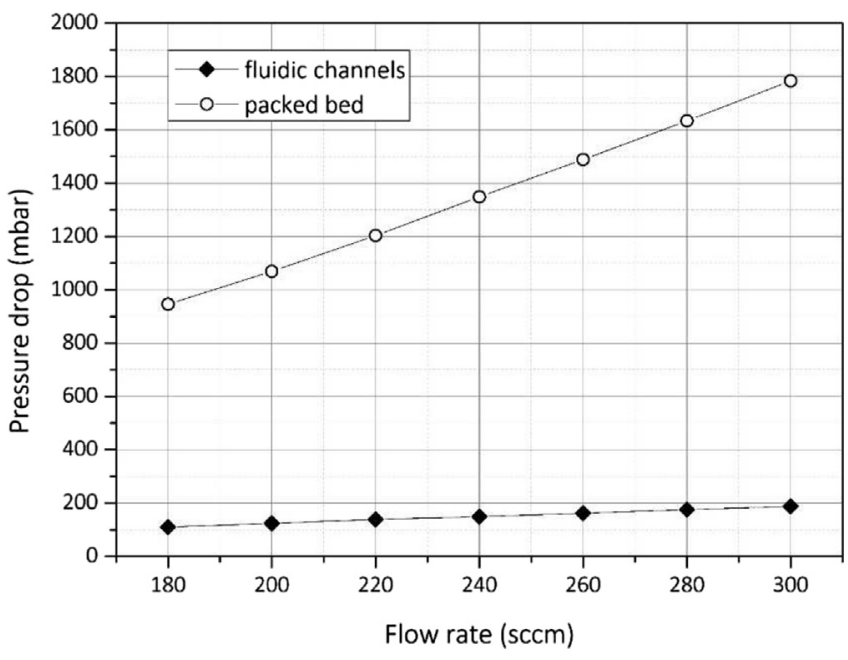

Fig. 7. Pressure drop of the LTCC micro-reactor with and without packed-bed as a function of the supplied air flow rate.

with packed catalyst. This pressure drop in general exceeded 1 bar

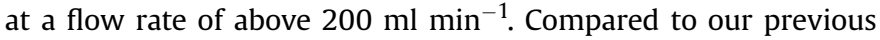
work [29] on glass-based micro packed-bed reactors, the high pressure drop in the LTCC micro-reactor was ascribed to the low porosity ( 0.38$)$ of the packed bed. Although high pressure drop would require more energy for pumping reactants into the reformer, such a hold-up can enhance the dispersion of gas reactants within the bed and avoids reactants flowing through the bed by some "short-circuit" paths. This concern would be more severe for small-scale packed-bed reactors (reactor volume $<1 \mathrm{~cm}^{3}$ ) for gas-phase reactions, since the bed volume and the active catalyst surface area are limited. This issue needs to be considered especially for our symmetrical-flow design, as the short effective packed-bed length makes it more probable for imperfections to run over the whole length.

In the future, it might be advisable to use porous spherical supports instead of YSZ spheres for increasing the bed porosity [37]. Alternatively, monolithic catalysts are recommended, i.e. stainless steel felts with doped catalyst [41-43]. Those monolithic feltsupported catalysts feature high porosity and can be directly inserted into the LTCC micro-reactor without using filling techniques. Additionally, the continuity and relatively high thermal conductivity of such support material enhances internal heat transfer for a higher efficiency of syngas production. Finally, the relatively ordered pore structure and elasticity ("springiness") of the felt allows complete filling of the packed-bed chamber volume, essentially precluding short circuits and thereby enhancing reliability.

\subsection{Thermal characterization}

The temperature at the thick-film Pt heaters of the LTCC microreactor was determined from their calibrated resistance as a function of temperature. The calibration was carried out by means of a thermocouple attached inside of the empty reactor chamber close to the thick-film heaters. Fig. 8a shows a typical plot of measured relative resistance $\left(R_{\mathrm{t}} / R_{\mathrm{ref}}\right)$ values as a function of the temperature difference $(\Delta T)$ to the reference temperature $\left(T_{\text {ref }}=25^{\circ} \mathrm{C}\right)$ upon heating. A second-order function (Equation (6)) was used to fit the result, thus deriving both, the linear temperature coefficient of resistance, $a$, and the parabolic temperature coefficients of resistance, $b$. The following numbers yielded the best fit for the larger outer heater (whose temperature was taken to be the nominal one, $\left.T_{\mathrm{op}}\right): a=(3.105 \pm 0.098)$ $\times 10^{-3} \mathrm{~K}^{-1}$ and $b=(-4.858 \pm 0.290) \times 10^{-7} \mathrm{~K}^{-2}$.

Fig. $8 \mathrm{~b}$ depicted the measured temperature at the hot-zone, i.e. at reforming chamber area, and the cold-zone under steady-state conditions as a function of supplied electrical heating power. Steady-state conditions were defined to be reached when the temperature changed by less than $5 \%$ during at least $10 \mathrm{~min}$. During the measurement, the hot-zone was covered by the thermal insulation blocks mentioned previously for minimizing heat losses by convection and radiation. As the supplied electrical power increased to ca. $5.4 \mathrm{~W}$, the temperature at the hot-zone was reaching about $620^{\circ} \mathrm{C}$. At the same time, the temperature at the cold-zone remained below ca. $80-90{ }^{\circ} \mathrm{C}$ for all levels of applied electrical power, for a total experimental duration of $2 \mathrm{~h}$.

Moreover, the temperature profile over the LTCC micro-reactor was also evaluated via a thermographic approach, in which the top side thermal insulation block was removed for convenience of observation (see Fig. 8c). In the hot-zone, especially in the area where the packed-bed chamber was beneath, the thermal distribution was relatively homogenous at an average temperature of $400^{\circ} \mathrm{C}$. The temperature in the cold zone of the LTCC micro-reactor stayed below $80^{\circ} \mathrm{C}$. A large thermal gradient profile $\left(\Delta T>200^{\circ} \mathrm{C}\right)$ was observed at the $7 \mathrm{~mm}$ long bridges of the LTCC micro-reactor, showing that the chosen materials, in combination with the inclusion of air gaps in our cantilever design, effectively reduced the heat flux from the hot-zone to the cold-zone and isolated the thermal energy within the targeted area.
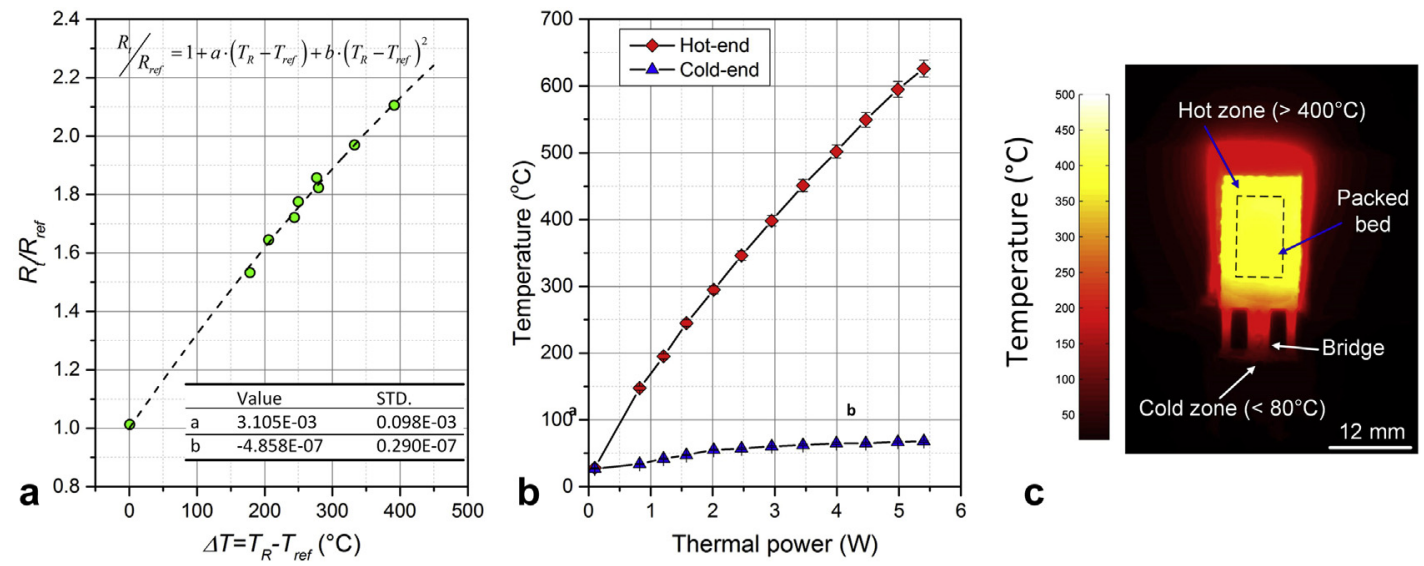

C

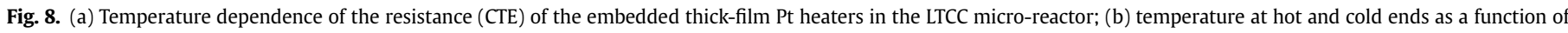

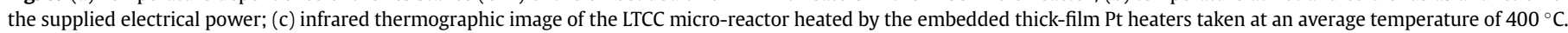


The detailed thermal analysis made in the reference [27] showed that the major thermal loss mechanisms were convection and radiation. This bridge design has been approved being appropriate for a $T_{\mathrm{op}}$ above $500{ }^{\circ} \mathrm{C}$, while keeping the temperature at the cold-end below $120^{\circ} \mathrm{C}$, thereby allowing standard fluidic/electrical connections to be used, e.g. tin-based solder for electrical interconnections for working temperatures below $170{ }^{\circ} \mathrm{C}$. Regarding to the fluidic connections, the integration of cold-zone made it possible to use polymeric adhesive for the hermetic sealing of tubes and connectors, and minimize thermal expansion issues in the fluidic junction. For example, the epoxy glue used in this work has a working temperature below $200{ }^{\circ} \mathrm{C}$. A moderate degree of heating of the cold-zone, up to $60-100{ }^{\circ} \mathrm{C}$, is actually advantageous for our application, as it avoids the condensation of water at the outlet from any integrated reactor element: reforming micro-reactor, combustion micro-reactor or $\mu$-SOFCs.

In our previous work [29], a high-temperature micro-reactor was developed using glass materials (thermal conductivity, $k=1.16 \mathrm{~W} \mathrm{~m}^{-1} \mathrm{~K}^{-1}$ ) with a $75 \mathrm{~mm}$ long cantilever beam design, which allowed a temperature difference $\Delta T \approx 600{ }^{\circ} \mathrm{C}$ between the hot-zone and the cold-zone. The thermal resistance of such a glass cantilever beam shape was estimated to be $\sim 2000 \mathrm{~K} \mathrm{~W}^{-1}$. Although this number was better than for the LTCC bridge design $\left(\sim 250 \mathrm{~K} \mathrm{~W}^{-1}\right)$, it must be noted that the thermal decoupling effect of the LTCC micro-reactor has fulfilled our needs. The better structurability in LTCC technology allows for far higher degrees of miniaturization and integration possibilities. Actually, the higher thermal conductivity of LTCC could be somewhat advantageous, as it helps the hot zone to achieve more isothermal conditions at the reactor walls. Finally, as the dominant convection and radiation losses scale with size, an LTCC-based $\mu$-SOFC system is ultimately expected to have lower thermal losses than the glass-based one.

\subsection{Chemical characterization}

\subsubsection{Catalytic partial oxidation performance}

The catalytic partial oxidation (CPOX) of propane in the LTCC micro-reactor was first evaluated at various $T_{\mathrm{op}}$, in the constanttemperature mode, where the temperature of the integrated thick-film Pt heaters was regulated, resulting in a constant average temperature across the LTCC micro-reactor, as there was an efficient heat exchange between reactor walls and heaters.

As described above, the catalytic packed bed in the LTCC microreactor comprised catalyst nanoparticles adhering as thin layers on the surfaces of dense YSZ spheres (see Fig. 5c). The major paths of the reactants towards and from the catalyst nanoparticles went through the voids between the YSZ spheres, whereas the pores structure within the catalyst nanoparticles was quite limited and the reactants transport in this region was negligible. Therefore, an external mass transfer of propane/air reactants over the surface of catalysts determined the mass diffusion to the CPOX process. Such an external mass transfer behaviour can be practically characterized by the Carberry number (Ca), a ratio between the observed reaction rate and the maximum external mass transfer [44]. As defined in Equation (7) [45], $C_{\mathrm{b}}$ stands for the propane species bulk concentration and $a^{\prime}$ represents the specific external surface of used catalyst. The mass transfer coefficient $\left(k_{\mathrm{g}}\right)$ used in determining Ca is dependent of the characteristic length of the packed-bed $\left(D_{\mathrm{p}}\right)$, the molecular diffusion coefficient $\left(D_{\mathrm{m}}\right)$, and the dimensionless Sherwood number, Sh (see Equation (8)). The Sh number is estimated from the Foressling equation (see Equation (9)) for the packed-bed reactor [46].

In Table 3, Ca was evaluated for a flow rate of $1.29 \times 10^{-6} \mathrm{~m}^{3} \mathrm{~s}^{-1}$ of propane/air mixed gas at $T_{\mathrm{op}}=500{ }^{\circ} \mathrm{C}$. The observed conversion rate of the propane was found to be $r_{\mathrm{obs}} \approx 0.06 \mathrm{~mol} \mathrm{~kg}^{-1} \mathrm{~s}^{-1}$, which was calculated by the propane concentration measured at inlet and outlet of the LTCC micro-reactor. The used value of molecular diffusivity of propane in air, $D_{\mathrm{m}}=1.45 \times 10^{-5} \mathrm{~m}^{2} \mathrm{~s}^{-1}$, was estimated based on experimental values [47] at $T_{\mathrm{op}}=500{ }^{\circ} \mathrm{C}$ according to the Stokes-Einstein equation [48] (see Equation (10)), where the viscosity data of propane were obtained from Vogel's work [49]. All parameters used in the evaluation were in SI units. The porosity of close-packed YSZ beads corresponded to 0.38 , as measured before, and its characteristic length, $L^{\prime}=2.50 \times 10^{-5} \mathrm{~m}$, was estimated by (see Equation (11)) due to its spherical shape and an average particle size of $0.15 \times 10^{-3} \mathrm{~m}$. The resulting value showed that the $\mathrm{Ca} \approx 8.2 \times 10^{-7}$ was significantly lower than unity ( $\mathrm{Ca}<<1$ ). Dekker et al. [44] suggested that Ca should be smaller than 0.05 as a criterion for negligible transport effects in gas phase steady-state heterogeneous catalytic reactions. Therefore, from our estimated Ca value, it was concluded that the LTCC micro-reactor was operating in a kinetics-limited region. The external mass diffusion was negligible as compared to the "fast" reaction rate of the CPOX process.

As shown in Fig. 9a, the propane conversion rate steadily increased to $89.6 \%$ as $T_{\text {op }}$ was raised from $390{ }^{\circ} \mathrm{C}$ to $642{ }^{\circ} \mathrm{C}$. Such temperature dependence is also observed in the syngas yield over the same $T_{\mathrm{op}}$ range. At $T_{\mathrm{op}}=642{ }^{\circ} \mathrm{C}$, the syngas yield corresponded to $71 \%$, indicating a production rate of $9.7 \mu \mathrm{mol} \mathrm{s}{ }^{-1}$. These results have demonstrated a good reforming performance at much lower temperatures as compared to previously developed micro-reactors. Mitchell et al. [10] demonstrated a ceramic alumina-based microreactor containing several identical microchannels $\left(3 \times 0.4 \times 0.14 \mathrm{~mm}^{3}\right)$ in parallel, into which Ru-coated SiC catalytic monoliths were mounted. This device achieved steam reforming of propane at high temperatures $\left(800^{\circ} \mathrm{C}-1000{ }^{\circ} \mathrm{C}\right)$, with complete reaction of propane above $850{ }^{\circ} \mathrm{C}$, and an $\mathrm{H}_{2}$ production rate of $12.4 \mathrm{sccm}$ at $800^{\circ} \mathrm{C}$. The high conversion rate is ideal for avoiding coking. However, this micro-reactor had no thermal decoupling structure and therefore required long alumina tubing for the fluidic connection. It cannot be considered as a stand-alone micro reactor for integration into a system.

\subsubsection{The effect of the metallic thermal spreader}

In this study, we used a LTCC micro-reactor without the thermal spreader, but otherwise identical, as a reference to evaluate the impact of the thick-film thermal spreader on the CPOX performance of the LTCC micro-reactor. Both LTCC micro-reactors, with and without the thermal spreader, carried out the CPOX of propane

Table 3

External mass transfer properties of the LTCC micro-reactor.

\begin{tabular}{ll} 
& $\begin{array}{l}\text { Reactants total flow rate at } \\
\text { operating temperature } V_{\text {tot }} \mathrm{m}^{3} \mathrm{~s}^{-1}\end{array}$ \\
\hline & $V_{\text {tot, } 1}=1.29 \times 10^{-6}$ \\
Observed reaction rate, $r_{\mathrm{obs}}$ & $0.06\left[\mathrm{~mol} \mathrm{~kg}^{-1} \mathrm{~s}^{-1}\right]$ \\
Bulk concentration of propane, $C_{\mathrm{b}}$ & $1.52\left[\mathrm{~mol} \mathrm{~m}^{-3}\right]$ \\
Operating temperature $T_{\mathrm{op}}$ & $773[\mathrm{~K}]$ \\
Porosity & 0.38 \\
Packed-bed axis cross-section, $A$ & $14\left[\mathrm{~mm}^{2}\right]$ \\
Propane viscosity at $773 \mathrm{~K}, \mu$ & $0.02\left[\mathrm{~Pa} \mathrm{~s}^{2}\right]$ \\
Molecular diffusion coefficient & $14.5\left[\mathrm{~mm}^{2} \mathrm{~s}^{-1}\right]$ \\
$\quad$ of propane at $773 \mathrm{~K}, D_{\mathrm{m}}$ & $478\left[\mathrm{~g} \mathrm{~m}^{-3}\right]$ \\
Density of inlet fluid mixture at $T_{\mathrm{op}}, \rho$ & $25[\mu \mathrm{m}]$ \\
Characteristic length, $L$ & $19.9\left[\mathrm{mg}^{-1}\right.$ \\
Mass of loaded catalyst, $m_{\mathrm{cat}}$ & $1.41\left[\mathrm{~m} \mathrm{~s}^{-1}\right]$ \\
Mass transfer coefficient of propane, $k_{\mathrm{g}}$ & $2.05 \times 10^{-2}$ \\
Reynolds number, Re & 4.86 \\
Schmidt number, Sc & 2.44 \\
Sherwood number, Sh & $8.2 \times 10^{-7}$ \\
Carberry number, Ca &
\end{tabular}



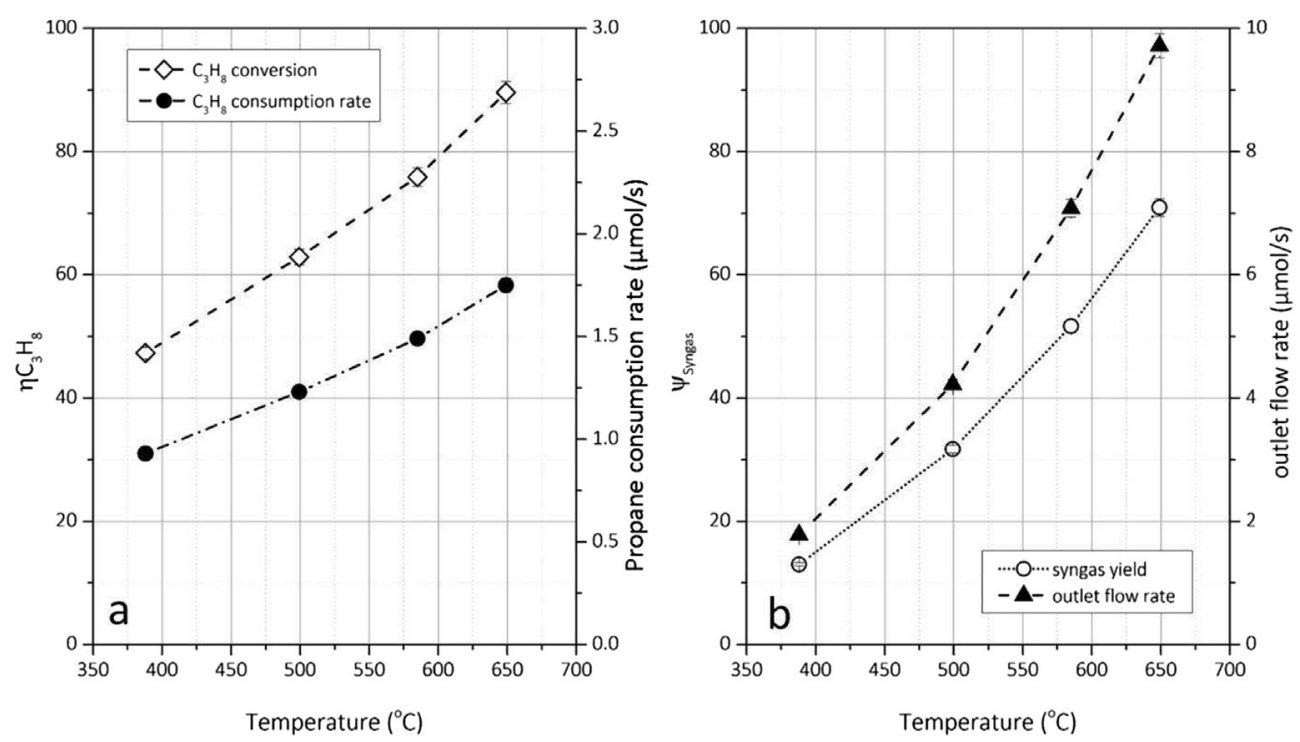

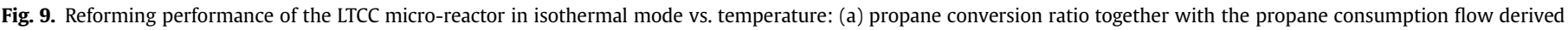
from the propane outlet flow; and (b) syngas outlet flow shown together with the syngas yield coefficient.

at varied $T_{\mathrm{op}}$ and supplied by propane/air mixture at $30 \mathrm{sccm}$. A thermographic observation was made at right top of the hot-zone of the LTCC micro-reactors and summarized as an average temperature line-scan profile for the temperature uniformity comparison (see Fig. 10). Under same test conditions, the comparison of both LTCC micro-reactors has shown that the one with the thickfilm thermal spreader had better temperature uniformity. It was seen from Fig. 10 that a two-humped temperature profile formed across the LTCC micro-reactor without thermal spreader, which indicated temperature spikes in the bed entrances at double sides and relatively lower temperature at the centre due to the inefficient heat transfer within the packed-bed. In contrast, the reactor with the thermal spreader showed relatively flat temperature profile in this area. The temperature spikes at sides were hardly observed and the temperature difference between the side and the centre was much smaller than that in the reformer without thermal spreader.

Correspondingly, gas analysis results (see Fig. 11) revealed the beneficial effect of the thermal spreader, through increased heat transfer and temperature uniformity, on the syngas production

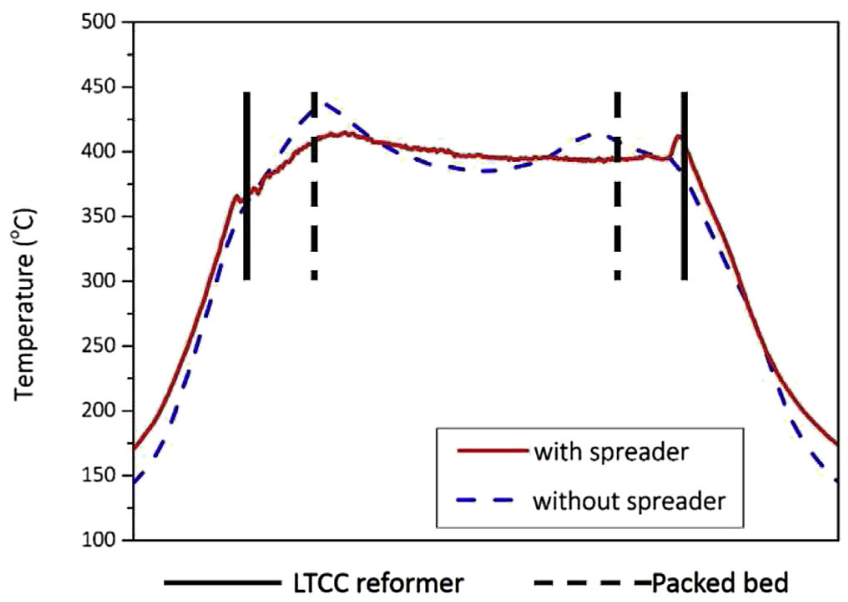

Fig. 10. Temperature line profile across the LTCC micro-reactor vertical to the inlet main channels (inlets: left and right, outlet in the centre) with and without metallic thermal spreader during a partial oxidation reaction of propane at $500{ }^{\circ} \mathrm{C}$ with a flow rate of $30 \mathrm{sccm}$ at $\mathrm{C} / \mathrm{O}=0.8$ of propane/air feed. performance, as determined from propane conversion and syngas yield. At $T_{\mathrm{op}}=500{ }^{\circ} \mathrm{C}$, the LTCC micro-reactor with thermal spreader delivered a propane conversion of $63 \%$ and a syngas yield of $31.7 \%$, compared to $57 \%$ and $23.5 \%$ without thermal spreader, respectively. Using thermal spreaders for better chemical process performance has been shown to be beneficial in other studies. Federici et al. [50] studied the influence of using copper blocks as thermal spreaders on the thermal uniformity of a catalytic microcombustor, and shown the resulting enhancement of thermal conductivity at reactor walls that allowed nearly uniform temperatures. Both Federici et al. [50] and Karim et al. [51] confirmed that thermal inserts with higher thermal conductivity did improve the thermal uniformity over the micro-reactor, with an effect of increasing thermal conductivity and/or spreader thickness. The bulk thermal conductivities of silver and LTCC are about $429 \mathrm{~W} \mathrm{~m}^{-1} \mathrm{~K}^{-1}$ and $3.3 \mathrm{~W} \mathrm{~m}^{-1} \mathrm{~K}^{-1}$ at $25^{\circ} \mathrm{C}$, respectively. According to our observation, the thermal spreader and the upper reactor wall had similar thicknesses. This means that adding the thermal spreader would enhance the reactor wall thermal conductivity by more than 10 times, even accounting for the lower thermal conductivity of thick-film silver that is further reduced at high temperature in the actual case.

On the other hand, it can be concluded that the syngas production efficiency in our testing system was highly dependent on how effectively the thermal energy propagated from the upstream combustion zone to the downstream reforming zone (syngas forming region). Using materials with high thermal conductivity as reactor construction materials, i.e. silicon or silicon carbide, can greatly promote the heat transfer efficiency of the CPOX reactions, at the cost of increased heat dissipation and electrical input power, though. Thus, high thermal conductive materials can only be partially implanted into the reaction zone, preferentially at interfaces sandwiched between hot zones, such as between the reactor and the fuel cell membrane module.

\subsubsection{The influence of the inlet flow configuration}

To evaluate the effect of the symmetrical-flow design in our LTCC micro-reactors on the CPOX performance (design V in Fig. 12), it was compared with an LTCC-based conventional packed-bed micro-reactor with a horizontal flow (design $\mathrm{H}$ in Fig. 12) that had same packed-bed volume and catalyst loading. In the 

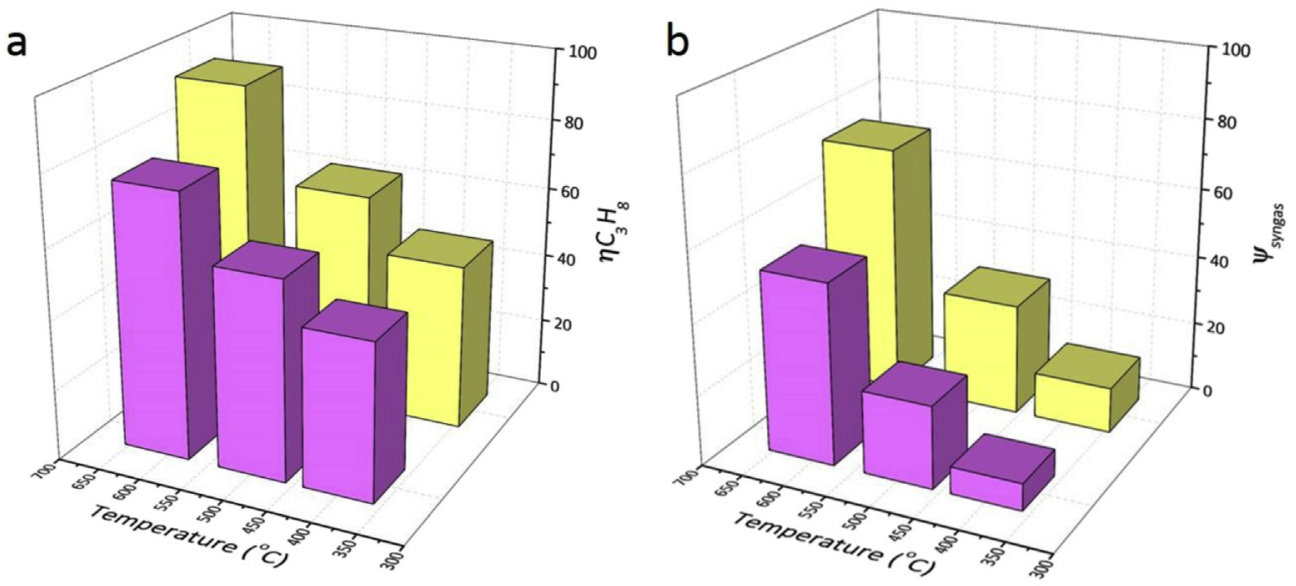

Without thermal spreader

With thermal spreader

Fig. 11. The influence of metallic thermal spreader on the reforming performance of the LTCC micro-reactor: (a) propane conversion and (b) syngas yield.

conventional H-design, the fluid flowed from one side to the other with a length-to-width ratio less than 1 . In the symmetrical-flow design (V), the gas reactants entered the bed from both long sides near the edge of the hot-zone and exited the bed at its centre via the heater layer. In such a way, it was possible - for a given width and height of the packed bed - to double the effective catalyst cross section.

The temperature profile during the reforming was evaluated at both micro-reactors by thermography, while they were kept at same $T_{\mathrm{op}}$ and fed with the same flow of propane/air mixture. The thermographs (Fig. 13) show that a large ellipse-shape hot spot was formed in the H-design near the bed entrance. The temperature dropped towards the exit, leading to a temperature decrease of ca. $120{ }^{\circ} \mathrm{C}$ within the bed. By contrast, in the V-design (see Fig. 13b), only small hot spots were formed at its double-side bed entrances, with a temperature difference between entrance and exit of ca. $70{ }^{\circ} \mathrm{C}$, thus much smaller than in the $\mathrm{H}$-design. In addition, the $\mathrm{V}$ design had a better homogenous temperature profile in the downstream region above the exits as compared to the exit region with the H-design.

The syngas production performance of both designs were examined under constant-temperature mode with a $30 \mathrm{sccm}$ flow rate of propane/air feed at $T_{\mathrm{op}}=500 \pm 10^{\circ} \mathrm{C}$ and $T_{\mathrm{op}}=610 \pm 10^{\circ} \mathrm{C}$.

\section{Symmetrical-flow design (V)}
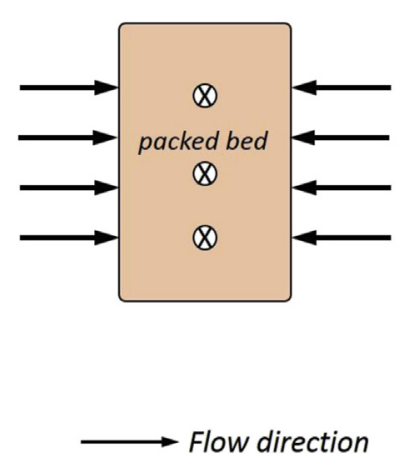

\section{$\otimes$ Flow-out direction}

Fig. 12. A schematic of symmetrical-flow design and horizontal flow design of the LTCC micro-reactor.
As shown in Fig. 14, the propane conversion for the V-design was $57 \%$ at $T_{\mathrm{op}}=500 \pm 10{ }^{\circ} \mathrm{C}$ and $76 \%$ at $T_{\mathrm{op}}=610 \pm 10^{\circ} \mathrm{C}$, lower than that for the H-design, where the conversion was $63 \%$ and $85 \%$, respectively. However, the hydrogen, carbon monoxide and their total syngas yields were much higher in the V-design, with the difference gradually increasing as $T_{\text {op }}$ increases. Therefore, the LTCC micro-reactor in V-design has delivered a better performance in terms of syngas production, although less convection of propane found in comparison with the H-design.

In the V-design, the cross-section area of the packed bed at both entrances was about $27 \mathrm{~mm}^{2}$, almost five times larger than that in the $\mathrm{H}$-design. This corresponded to a much larger catalyst contact area at the packed-bed entrance, given that both designs shared the same packed-bed porosity and catalyst. Certainly, the double-side, large catalyst contact area at the bed entrance diluted the concentration of reactants, leading to less formation of hot spots, which was confirmed by our qualitative thermographic results. As stated previously, the reaction paths of the CPOX process at the bed entrance is dominated by (exothermic) combustion and the (endothermic) syngas formation depends on the temperature in the downstream. In the H-design, the high concentration of propane at the bed entrance led to the intensive formation of hot spots and therefore yielded a higher conversion rate of propane than that in the V-design. On the other hand, the long, double-entrance configuration in the V-design yielded less thermal energy at the bed entrance due to diluted combustion, diminishing the hot-spot formation.

A higher syngas yield was found in the V-design. This was because the symmetrical flow design shortened the axial length of the packed bed, in other words, enhancing the heat transfer between the exothermic combustion at the bed entrance and the endothermic reforming reactions in the downstream. More thermal energy generated from the combustion region was transferred to the downstream, leading to a higher yield of syngas as compared to the H-design, where the long axial bed inhibited the efficient heat transfer within the bed. However, for achieving high syngas yield, thermal energy must be provided to the downstream efficiently, which can be supplied by either the upstream combustion reaction, or from an external heating source. Enhanced heat transfer within the bed improves syngas production efficiency, and can be realized through (i) the use of thermal spreaders, (ii) by using packed-bed materials with higher thermal conductivities, or (iii) by improving the design to shorten heat transfer paths. Our V- 


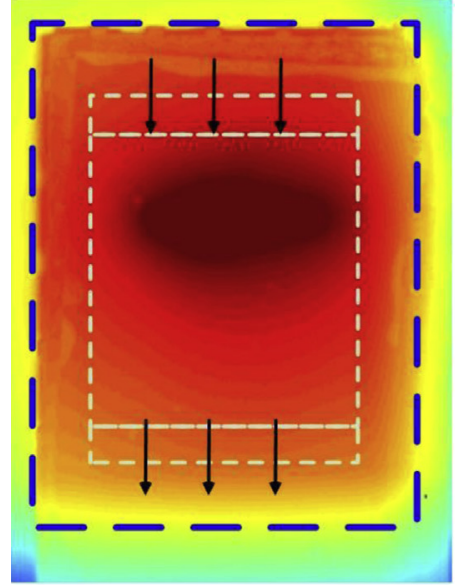

$\mathrm{H}$ - design

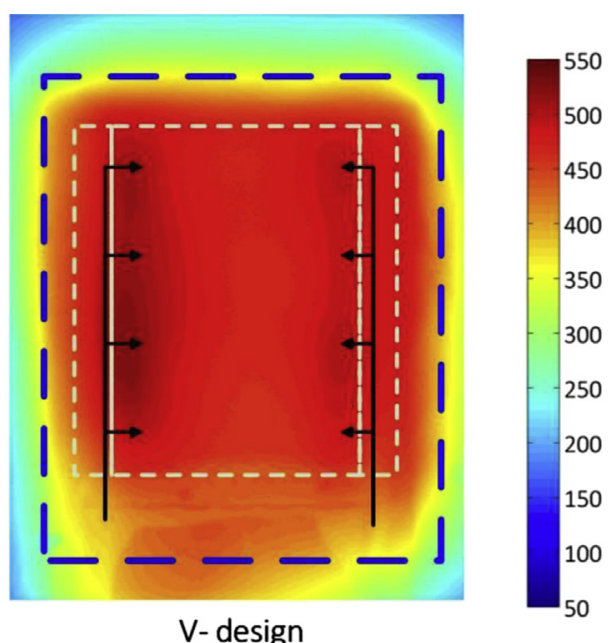

$6 \mathrm{~mm}$

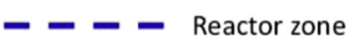

---- Catalytic bed

Fig. 13. Infrared images of H-design and V-design of the LTCC micro-reactors during reforming in the isothermal mode.

design LTCC micro-reactor adopted the latter approach, which considerably increased the effective bed cross-section, while decreasing its axial bed length. Besides, the entrances were placed at the long sides, where higher thermal losses occurred, thereby effectively serving as thermal guards and heat sources for the endothermic reforming reactions at the centre of the packed-bed, improving the syngas yields. In the future, we would propose a further optimized design for the CPOX process, which may be achieved by implanting a parametric entrance design on how the flow goes from the entry to the centre, further decreasing heat dissipation paths for the syngas production. But a compromise must be made between an ideal design and feasibility of the LTCC fabrication process.

\subsubsection{Thermally self-sustaining operation}

In the self-sustaining mode, the LTCC micro-reactor was operated without resistive heating to assess the heat produced by the reforming process. Nevertheless, resistive pre-heating up to $\sim 450{ }^{\circ} \mathrm{C}$ was made without fuel gas. Then the propane/air mixture $(\mathrm{C} / \mathrm{O}=0.8)$ was admitted at flow rates of $80 \mathrm{ml} \mathrm{min}^{-1}, 95 \mathrm{ml} \mathrm{min}^{-1}$ or $105 \mathrm{ml} \mathrm{min}^{-1}$, and the electrical heating power was regulated to zero by the circuit, as the temperature rose above the $450{ }^{\circ} \mathrm{C}$. The CPOX process performance under the self-sustained mode was evaluated in the LTCC micro-reactor with integrated thick-film thermal spreader and symmetrical flow design, which had been proved to improve the syngas yield through enhanced heat transfer within the packed-bed. For this purpose, the LTCC micro-reactor was heated up to ca. $450{ }^{\circ} \mathrm{C}$ by electrical power. Then the reactants were supplied to the LTCC micro-reactors and the thermally self-sustaining CPOX process started. The supplied electrical power was automatically adjusted for maintaining the $T_{\mathrm{op}}$ at the designated level of $450{ }^{\circ} \mathrm{C}$. Fig. 15 shows the supplied electrical power as well as $T_{\mathrm{op}}$ before and after the self-sustaining CPOX process started. It took about $5 \mathrm{~min}$ to reach $T_{\mathrm{op}}$ of $450^{\circ} \mathrm{C}$ by external heating.
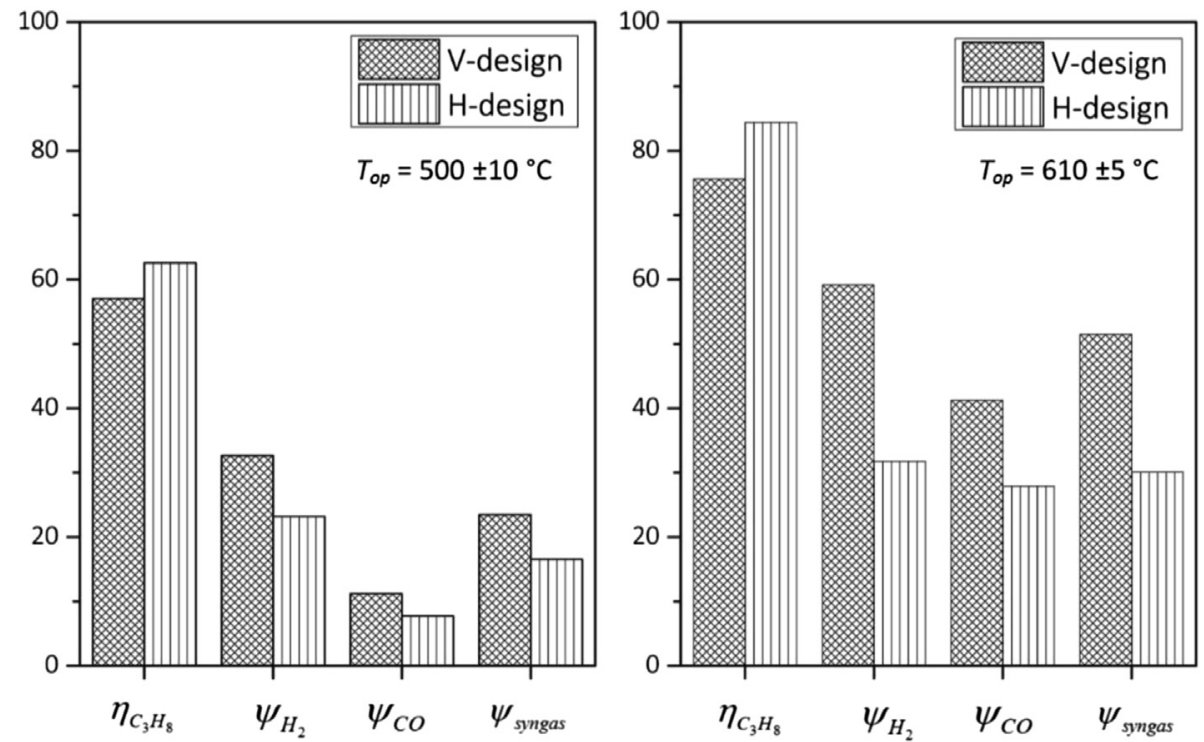

Fig. 14. Reforming performance comparison between V-design and H-design of LTCC micro-reactors. 


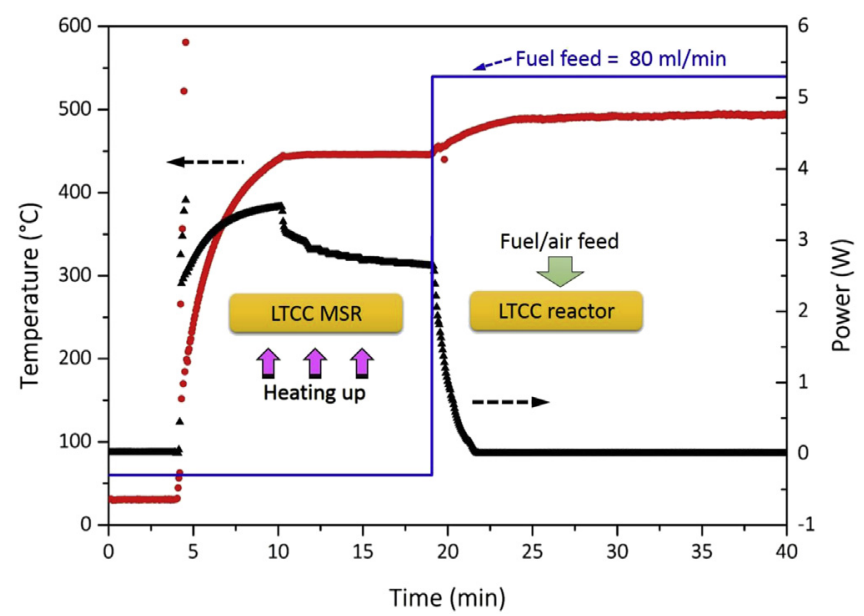

Fig. 15. Temperature and Pt thick-film heater power of the LTCC micro-reactor during its thermally self-sustaining process with a preheating phase. (MSR $=$ micro (structured) reactor)

This temperature was stabilized with a steady-state electrical power consumption of ca. $2.7 \mathrm{~W}$. The ramp up power consumption was much lower than the one achieved with the glass-based microreformer previously developed in our group [16], which is mainly due to the smaller thermal mass of the LTCC micro-reactor. When $80 \mathrm{sccm}$ of propane/air mixture were fed into the LTCC microreactor, the CPOX process took over the heating within a few seconds. The thermal energy produced from the CPOX process raised the operation temperature $T_{\mathrm{op}}$ to $495^{\circ} \mathrm{C}$ within less than $5 \mathrm{~min}$. No electrical power was needed for maintaining the LTCC microreactor at this high temperature. We showed here for the first time the use the electronic approach to characterize a selfsustaining CPOX process.

We analysed propane conversion as well as syngas yield for various feed flow rates (Table 4). As the feed flow rate increased from 80 to $105 \mathrm{sccm}$, both propane conversion and syngas yield were improved, corresponding to an increase of the temperature from $492{ }^{\circ} \mathrm{C}$ to $544^{\circ} \mathrm{C}$. At a feed supply of $105 \mathrm{sccm}$, the LTCC microreactor was able to deliver, independently of an external thermal source, a $\mathrm{H}_{2}$ production rate of $16 \mathrm{sccm}$ and a $\mathrm{CO}$ production rate of $71 \mathrm{sccm}$, corresponding to a heating power of $W_{\mathrm{LHV}}=1.14 \mathrm{~W}$ (LHV = low heating value) and a power density of $1322 \mathrm{~W} \mathrm{~L}^{-1}$ (see Table 4). The complete reaction of such syngas flow would correspond to a fuel cell current of $0.85 \mathrm{~A}$, thus around $0.5 \mathrm{~W}$ power generation. Considering present $\mu$-SOFC performance [52], this power is achieved with an active area of $0.5-1 \mathrm{~cm}^{2}$, thus about the footprint of our micro-reactor. Although other micro reactor studies demonstrated good yields of hydrogen at higher operation temperatures $\left(>800^{\circ} \mathrm{C}\right)$ in tube-furnaces [10], our work demonstrated for the first time a ceramic micro-reactor that delivers syngas in a self sustained way with a sufficient output for a $\mu$-SOFC membrane with the same footprint.

The increased hydrocarbon conversion rate and syngas yield with increasing gas space velocity (GSV) is consistent with other works [22,53], which indicated that the initial flows were not high enough to overcome diffusion and heat transfer resistance of the packed bed. Higher flow rates promote forced thermal convection, leading to increased heat transfer to the exit region where the syngas production reactions occur. In addition, the temperature increase with higher propane flow rate was certainly also beneficial for raising the reaction rates, and all effects together result in an overall increase in propane POX performance.

As discussed previously, both the symmetrical-flow design and the use of thermal spreader can improve the heat transfer of the packed bed for better syngas production. The reforming results obtained in the self-sustained mode however were generally lower than the results in the constant-temperature mode. This indicates that the thermal uniformity of the CPOX process in the constanttemperature mode (with the help of the micro heaters) was better than in the self-sustained mode. And this further indicates that the heat transfer within the packed bed plays a very critical role for the CPOX process. Therefore, the thermal conductivity of the packed bed itself must be improved for better syngas production performance. For example, the use of $\mathrm{SiC}$ monolithic catalyst supports can be considered, due to their high thermal conductivity ( $48 \mathrm{~W} \mathrm{~m}^{-1} \mathrm{~K}^{-1}$ at $500{ }^{\circ} \mathrm{C}$ [54]). Mitchell and his co-workers [10,11] have demonstrated a $\mathrm{SiC}$ monolithic catalyst with ordered pore structure for high-temperature $\left(>800^{\circ} \mathrm{C}\right)$ reforming reactions. Such $\mathrm{SiC}$ monolithic catalyst supports combine a high surface area for catalyst doping with a high thermal stability/conductivity, as well as a moderate pressure drop across the micro-reactor. Another available option for enhancing the heat transfer within the packed bed is the use of high-temperature stainless steel felts, e.g. FeCrAlloy, as catalyst supports [42-44]. However, more attention must be paid to the assembly process of those monolithic catalyst supports into the micro-reformer; the thermomechanical and thermal properties of the catalyst support, the reformer structure and the used joining technique must be compatible and carefully chosen.

\section{Conclusions}

We have developed a meso-scale high-temperature microreaction system based on LTCC and thick-film technologies for an on-site syngas production application. The integrated thick-film heaters enabled heating of the LTCC micro-reactors to above $600{ }^{\circ} \mathrm{C}$ at a total power consumption of $5 \mathrm{~W}$. The novel design of air gap bridge structures led to an efficient thermal decoupling across the device, resulting in well-defined hot and cold temperature zones. The cold zone allows for standard fluidic/electrical interconnections, as well as the easy mechanical mounting. Such a convenient structure significantly increased the flexibility and portability of the micro-reactor system.

An improved LTCC structuration process was developed for creating sub-mm scale fluidic structures within the reactor, making it possible to integrate intact complex fluidic channels and cavities for mixing, packed-bed and transportation. A gas distributor submodule, validated by a simple numerical model, has been successfully developed within the reformer. This distributor increased the pressure drop over the packed bed, resulted in a more

Table 4

The CPOX performance of the LTCC micro-reactor in the thermally self-sustaining mode.

\begin{tabular}{|c|c|c|c|c|c|c|}
\hline $\begin{array}{l}\text { Total inlet flow } \\
\text { rate sccm }\end{array}$ & $\begin{array}{l}\text { Propane flow } \\
\text { rate sccm }\end{array}$ & Reactor temperature $\left({ }^{\circ} \mathrm{C}\right)$ & $\mathrm{C}_{3} \mathrm{H}_{8}$ conversion $\eta_{\text {prop. }}$ & Syngas yield $\Psi_{\text {syngas }}$ & $\begin{array}{l}\text { Outflow rate of } \\
\mathrm{CO} \mu \mathrm{mol} \mathrm{s}{ }^{-1}[\mathrm{sccm}]\end{array}$ & $\begin{array}{l}\text { Outflow rate of } \\
\mathrm{H}_{2} \mu \mathrm{mol} \mathrm{s}^{-1}[\mathrm{sccm}]\end{array}$ \\
\hline 80 & 7.7 & 492 & $50.1 \%$ & $17.4 \%$ & 1.3 [19.6] & 5.0 [6.8] \\
\hline 95 & 9.2 & 524 & $55.6 \%$ & $25.2 \%$ & $3.0[43.0]$ & 8.0 [10.7] \\
\hline 105 & 10.1 & 544 & $60.2 \%$ & $32.5 \%$ & $4.9[71.0]$ & $10.7[14.4]$ \\
\hline
\end{tabular}


homogeneous flow, and was important to realize high reaction efficiency over a short reactor path.

Using Rh-metal catalyst dispersed by dense packed YSZ microspheres, the LTCC micro-reactor was able to deliver a syngas production rate in both isothermal- and thermal self-sustaining modes, $9.7 \mu \mathrm{mol} \mathrm{s}^{-1}$ and $4.4 \mu \mathrm{mol} \mathrm{s}{ }^{-1}$ respectively. The design of the LTCC micro-reactor was evaluated with respect to heat transfer enhancement during CPOX of propane for the syngas production. Important improvements were achieved by including a thermal spreader and a symmetrical-flow design, in terms of thermal uniformity over the reactor wall and heat transfer in the downstream, from the packed-bed entrance with its exothermic oxidation reactions to its end part with dominating reduction to form the final syngas components $\mathrm{H}_{2}$ and $\mathrm{CO}$. Moreover, the symmetrical-flow configuration, due to a shorter path for heat diffusion, could reduce hot-spot formation, in comparison with a conventional single-flow $\mu$-PBR design, and enhance the syngas production by facilitating the syngas reforming reactions in the downstream region. It is expected that the efficiency for syngas production will increase by using smaller YSZ micro-spheres, thus providing a higher surface to volume ratio for a more effective catalysis performance.

Overall, the presented LTCC device demonstrates a small, flexible high-temperature microreaction system that can be integrated within a $\mu$-SOFC power plant for portable power generation or directly be used for carrying out high-temperature chemical process applications, e.g. hydrocarbon reforming, nanoparticle synthesis, Fischer--Tropsch synthesis and so on.

\section{Acknowledgements}

The authors would like to thank Robert Büchel (ETHZ) for providing catalyst materials, and the Swiss National Science Foundation (contracts CRSI11_126830 and 200021_143424) for funding this work.

\section{References}

[1] A. Bieberle-Hütter, D. Beckel, A. Infortuna, U.P. Muecke, J.L.M. Rupp, L.J. Gauckler, S. Rey-Mermet, P. Muralt, N.R. Bieri, N. Hotz, M.J. Stutz, D. Poulikakos, P. Heeb, P. Müller, A. Bernard, R. Gmür, T. Hocker, J. Power Sources 177 (2008) 123-130.

[2] B. Jiang, P. Muralt, A. Renken, T. Maeder, 2014, in preparation.

[3] A. Qi, B. Peppley, K. Karan, Fuel Process. Technol. 88 (2007) 3-22.

[4] J.D. Holladay, Y. Wang, E. Jones, Chem. Rev. 104 (2004) 4767-4789.

[5] O. Younes-Metzler, J. Svagin, S. Jensen, C.H. Christensen, O. Hansen, U. Quaade, Appl. Catal. A Gen. 284 (2005) 5-10.

[6] X. Yu, S.-T. Tu, Z. Wang, Y. Qi, Chem. Eng. J. 116 (2006) 123-132.

[7] Y. Shin, O. Kim, J. Hong, J. Oh, W. Kim, S. Haam, C. Chung, Int. J. Hydrogen Energy 31 (2006) 1925-1933.

[8] J.-J. Park, Y. Shin, J.-H. Oh, C.-H. Chung, Y.-J. Huh, S. Haam, J. Ind. Eng. Chem. 15 (2009) 618-623.

[9] N. Hotz, N. Osterwalder, W.J. Stark, N.R. Bieri, D. Poulikakos, Chem. Eng. Sci. 63 (2008) 5193-5201.

[10] M. Mitchell, P.J.A. Kenis, Lab Chip 6 (2006) 1328.

[11] Christian, M. Mitchell, D.P. Kim, P.J.A. Kenis, J. Catal. 241 (2006) 235-242.

[12] L.R. Arana, S.B. Schaevitz, A.J. Franz, M.A. Schmidt, K.F. Jensen, J. Microelectromech. Syst. 12 (2003) 600-612.

[13] A.V. Pattekar, M.V. Kothare, J. Microelectromech. Syst. 13 (2004) 7-18.

[14] A. Bieberle-Hütter, A.J. Santis-Alvarez, B. Jiang, P. Heeb, T. Maeder, M. Nabavi, D. Poulikakos, P. Niedermann, A. Dommann, P. Muralt, A. Bernard, L.J. Gauckler, Lab Chip 12 (2012) 4894-4902.

[15] B. Jiang, P. Muralt, P. Heeb, A.J. Santis-Alvarez, M. Nabavi, D. Poulikakos, P. Niedermann, T. Maeder, Sens. Actuators B Chem. 175 (2012) 218-224.

[16] A.J. Santis-Alvarez, M. Nabavi, B. Jiang, T. Maeder, P. Muralt, D. Poulikakos, Chem. Eng. Sci. 84 (2012) 469-478.

[17] B. Scherrer, A. Evans, A.J. Santis-Alvarez, B. Jiang, J. Martynczuk, H. Galinski, M. Nabavi, M. Prestat, R. Tölke, A. Bieberle-Hütter, D. Poulikakos, P. Muralt, P. Niedermann, A. Dommanni, T. Maeder, P. Heeb, V. Straessle, C. Muller, L.J. Gauckler, J. Power Sources 258 (2014) 434-440.

[18] D. Belavič, M. Hrovat, G. Dolanc, M. Santo Zarnik, J. Holc, K. Makarovič Radioengineering 21 (2012) 195.
[19] C.-H. Sha, C.C. Lee, in: IEEE Transactions on Components, Packaging and Manufacturing Technology, 2011, pp. 1983-1987.

[20] B. Jiang, P. Muralt, T. Maeder, Erfurt, Germany, 2012, pp. 1-8.

[21] Z. Shao, S.M. Haile, J. Ahn, P.D. Ronney, Z. Zhan, S.A. Barnett, Nature 435 (2005) 795-798.

[22] A.J. Santis-Alvarez, M. Nabavi, N. Hild, D. Poulikakos, W.J. Stark, Energy Environ. Sci. 4 (2011) 3041.

[23] S. Hannemann, J.-D. Grunwaldt, B. Kimmerle, A. Baiker, P. Boye, C. Schroer, Top. Catal. 52 (2009) 1360-1370.

[24] K.L. Hohn, C.C. Huang, C. Cao, J. Nat. Gas Chem. 18 (2009) 115-123.

[25] I. Aartun, T. Gjervan, H. Venvik, O. Görke, P. Pfeifer, M. Fathi, A. Holmen, K. Schubert, Chem. Eng. J. 101 (2004) 93-99.

[26] I. Aartun, H.J. Venvik, A. Holmen, P. Pfeifer, O. Görke, K. Schubert, Catal. Today 110 (2005) 98-107.

[27] B. Jiang, P. Muralt, T. Maeder, 2014, in preparation.

[28] S. Marre, A. Adamo, S. Basak, C. Aymonier, K.F. Jensen, Ind. Eng. Chem. Res. 49 (2010) 11310-11320.

[29] B. Jiang, A.J. Santis-Alvarez, P. Muralt, D. Poulikakos, T. Maeder, 2014, in preparation.

[30] SCHOTT Technical Glass Solutions GmbH, Data sheets, 2010, p. 32.

[31] J. Spannhake, O. Schulz, A. Helwig, A. Krenkow, G. Müller, T. Doll, Sensors 6 (2006) 405-419.

[32] J. Kita, F. Rettig, R. Moos, K.H. Drüe, H. Thust, Int. J. Appl. Ceram. Technol. 2 (2005) 383-389.

[33] B. Jiang, J. Haber, L. Kiwi-Minsker, P. Muralt, T. Maeder, 2014, submitted.

[34] N. Hotz, N. Koc, T. Schwamb, AIChE J. 55 (2009) 1849-1859.

[35] K.W. Schlichting, N.P. Padture, P.G. Klemens, J. Mater. Sci. 36 (2001) 3003-3010.

[36] Molecular Technology (MolTech), 2013.

[37] V. Meille, Appl. Catal. A Gen. 315 (2006) 1-17.

[38] K. Malecha, D. Jurków, L.J. Golonka, J. Micromech. Microeng. 19 (2009) 065022.

[39] J. Dominik, G. Leszek, Int. J. Appl. Ceram. Technol. 7 (2010) 814-820.

[40] J. Haber, B. Jiang, N. Borhani, T. Maeder, J.R. Thome, A. Renken, L. Kiwi, in: 9th European Congress of Chemical Engineering (ECCE), 2013.

[41] B.C.B.C. Enger, J. Walmsley, E. Bjørgum, R. Lødeng, P. Pfeifer, K. Schubert, A. Holmen, H.J. Venvik, Chem. Eng. J. 144 (2008) 489-501.

[42] H. Pennemann, M. Dobra, M. Wichert, G. Kolb, Chem. Eng. Technol. 36 (2013) 1033-1041.

[43] A.R. Tadd, B.D. Gould, J.W. Schwank, Catal. Today 110 (2005) 68-75.

[44] F. Dekker, A. Bliek, F. Kapteijn, J. Moulijn, Chem. Eng. Sci. 50 (1995) 3573-3580.

[45] L. Kiwi, EPFL, Lectures 2013, pp. 30.

[46] A. Renken, L. Kiwi-Minsker, Microstructured Catalytic Reactors, first ed. Elsevier Inc., 2010.

[47] R.W. Elliott, H. Watts, Can. J. Chem. 50 (1972) 31-34.

[48] J.T. Edward, J. Chem. Educ. (1970) 261.

[49] E. Vogel, Int. J. Thermophys. 16 (1995) 1335-1351.

[50] J.A. Federici, D.G. Norton, T. Brüggemann, K.W. Voit, E.D. Wetzel, D.G. Vlachos, J. Power Sources 161 (2006) 1469-1478.

51] A.M. Karim, J.A. Federici, D.G. Vlachos, J. Power Sources 179 (2008) 113-120.

[52] J. An, Y-B. Kim, J. Park, T.M. Gür, F.B. Prinz, Nano Letters 13 (2013) 4551-4555.

[53] S.-A. Seyed-Reihani, G.S. Jackson, Catal. Today 155 (2010) 75-83.

[54] KYOCERA Corporation, Japan, 2013.

\section{Nomenclature}

Ma: Mach number

$T_{o p}$ : reactor operating temperature $\left({ }^{\circ} \mathrm{C}\right)$

Re: Reynolds number

$C / O$ : Fuel to oxygen ratio

$Q$ V: volumetric flow rate $\left(\mathrm{m}^{3} \mathrm{~s}^{-1}\right)$

$D_{H}$ : hydraulic number

A: cross-section area of the fluid channel $\left(\mathrm{mm}^{2}\right)$

$R_{i}$ : resistance at temperature $i$

$a, b$ : temperature coefficient of resistance

Ca: Carberry number $\left(\mathrm{m}^{3} \mathrm{~s}^{-1}\right)$

$C_{b}$ : bulk concentration $\left(\mathrm{mol} \mathrm{m}^{-3}\right)$

$a^{\prime}$ : specific external surface $\left(\mathrm{m}^{2}\right)$

$k_{\mathrm{g}}$ : Mass transfer coefficient $\left(\mathrm{m} \mathrm{s}^{-1}\right)$

$L^{\prime}$ : characteristic length $(\mathrm{m})$

$D_{m}$ : molecular diffusion coefficient $\left(\mathrm{m}^{2} \mathrm{~s}^{-1}\right)$

Sh: Sherwood number

$r_{\text {obs }}$ : observed conversion rate $\left(\mathrm{mol} \mathrm{kg}^{-1} \mathrm{~s}^{-1}\right)$

Greek symbol

$\varphi:$ C/O ratio

$\eta$ : propane conversion rate

$\psi_{i}$ : yields of $i$

$\rho_{f}$ : fluid density $\left(\mathrm{kg} \mathrm{m}^{-3}\right)$ 
$\mu_{i}$ : dynamic viscosity of fluid $i$ (Pa s)

$k$ : thermal conductivity $\left(\mathrm{W} \mathrm{m} \mathrm{m}^{-1} \mathrm{~K}^{-1}\right)$

Abbreviation

$\mu$-SOFCs: micro-scale solid oxide fuel cell

$S R$ : steam reforming

CPOX: catalytic partial oxidation

ATR/OSR: auto-thermal / oxidative steam reforming

CTE: coefficient of thermal expansion
BOP: balance of plant

LTCC: low temperature co-fired ceramics

PrOX: preferential CO oxidation

$\mu$-PBR: micro packed bed reactor

CFD: computational fluid system

YSZ: yttria stabilized zirconia

$T C R$ : temperature dependence of resistance

$L H V$ : low heating value

sccm: standard cubic centimetre per minute 